\title{
A Quasi-Experimental Evaluation of High Emitter Non-Compliance and its Impact on Vehicular Tailpipe Emissions in Atlanta, 1997-2001
}

1. Zia, Asim; Corresponding author. Mailing address: 3450 Mitchell Lane, Institute for the Study of Society and Environment, National Center for Atmospheric Research*, Boulder, CO 80301. Telephone 303-497-2890. Fax 303-497-8125. Email: asimzia@ucar.edu

2. Norton, Bryan G.; The School of Public Policy, Georgia Institute of Technology, Atlanta, GA

3. Noonan, Douglas S.; The School of Public Policy, Georgia Institute of Technology, Atlanta, GA

4. Rodgers, Michael O.; The School of Civil and Environmental Engineering, and the School of Public Policy, Georgia Institute of Technology, Atlanta, GA

5. DeHart-Davis, Leisha; The Department of Public Administration, University of Kansas, Lawrence, KA

Submitted on February 17, 2005

Revised and re-submitted on July 28, 2005

Transportation Research Part D: Transport and Environment

Final Version Available from:

Zia, A., Norton, B. G., Noonan, D. S., Rodgers, M. O., \& DeHart-Davis, L. (2006). A quasi-experimental evaluation of high-emitter noncompliance and its impact on vehicular tailpipe emissions in Atlanta, 1997-2001. Transportation Research Part D: Transport and Environment, 11(1), 77-96. doi:10.1016/j.trd.2005.09.002

* The National Center for Atmospheric Research is sponsored by National Science Foundation. 


\title{
A Quasi-Experimental Evaluation of High Emitter Non-Compliance and its Impact on Vehicular Tailpipe Emissions in Atlanta, 1997-2001
}

\begin{abstract}
A quasi-experimental evaluation is employed to assess the compliance behavior of high emitters in response to Atlanta's Inspection and Maintenance (IM) program between 1997 and 2001 and to predict the impact of compliance behavior on vehicular tailpipe emissions of ozone precursors, such as carbon monoxide (CO), hydrocarbons (HC) and nitrogen oxide (NO). Remote sensing data of a sample of approximately 0.8 million observations of on-road vehicles are matched with IM program data and vehicle registration data to identify the compliant and non-compliant high emitters. A mixed-pool time-series regression analysis is carried out to predict changes in the vehicular tailpipe emissions due to the compliance and non-compliance of the high emitters in the Atlanta airshed.
\end{abstract}

\section{Key Words}

Compliance, Environmental Regulation, Program Evaluation, Road Transportation 


\section{1: Introduction}

The broader aim of this paper is to study the environmental impact of human behaviors that emerge in response to policy interventions. More narrowly, this paper focuses on evaluating the compliance behavior of high-emitting vehicle owners (henceforth high emitters) in response to the policy intervention of vehicle inspection and maintenance (IM) programs.

Quasi-experiments provide a useful setting for policy analysis and evaluation to estimate the effects of policy interventions on the outcome variables for which the policies were introduced (Cook and Campbell 1979). Meyer (1995) provides a broad review of the previous quasi-experimental studies used in policy analysis. A quasiexperimental design is employed in this study to investigate in detail answers to the following two questions: (1) what is the probability of a high emitter complying with the rules of the Vehicle Inspection and Maintenance (IM) program in the Atlanta airshed? (2) What is the impact on the outcomes of vehicular emissions due to the compliance decisions of high emitters in the Atlanta airshed?

Previous literature (NRC 2001) suggests that vehicular tailpipe emissions of carbon monoxide (CO), hydrocarbons (HC) and nitrogen oxide (NO) are complex functions of three broad groups of parameters: human behaviors (in response to policy interventions and market mechanisms), vehicular characteristics (such as vehicle age, type, manufacturer), and the physical characteristics of the atmosphere (such as temperature and pressure). Figure 1 shows variables in these three broad groups of parameters that affect the vehicular tailpipe emissions in a conceptual framework of the quasi-experimental research design. 
As Figure 1 shows, the IM policy intervention leads to identification of two broad quasi-experimental groups of vehicle owners: the control and treatment groups. The control group represents groups of those vehicle owners who are not directly targeted by the policy intervention, such as those owning normal-emitting vehicles, the IM ineligible group from inside program, the rest-of-Georgia group from outside program, and the IMwaived groups ${ }^{\mathrm{i}}$. The treatment groups represent high emitters who are directly targeted by policy intervention. This paper presents decision models with perfect and imperfect information available to the program regulators and evaluators for classifying the vehicle owners in control and treatment groups. The decision model with imperfect information is applied to the case-study of the Atlanta airshed between 1997 and 2001 for identifying compliant and non-compliant high emitters and quantifying their impact on vehicular tailpipe emissions.

\section{2: A brief review of the literature and hypotheses of the study}

A recent National Research Council (NRC) report evaluating US IM programs states that "typically, less than $10 \%$ of the fleet contributes more than $50 \%$ of the emissions for any given pollutant...Thus, the largest potential reductions in emissions from IM programs are associated with a small number of high-emitting vehicles” (NRC 2001:5). Studies show that between $10 \%$ and $27 \%$ of vehicles that fail an IM test never pass the test and some of these failed vehicles are found operating in IM areas more than a year after their last test (Harrington et al. 1998; 1999; 2000; Lawson 1993; 1995; Lawson et al. 1990; Stedman et al. 1997; 1998; Wenzel 1999; Wenzel et al. 2000).

\footnotetext{
${ }^{\mathrm{i}}$ Note that the normal-emitting IM-eligible and waived vehicle owners are also targeted by the IM policy intervention, but the explicit objective of the IM program is to identify and repair high emitters.
} 
The motorist compliance rate refers to the percentage of vehicles that are required to participate in an IM program that actually do so (NRC 2001: 190). NRC (2001: 190193) recommends that all kinds of non-compliant behaviors need to be estimated in any realistic evaluation of the IM program and the negative effect caused by poor motorist compliance needs to be well documented. As recommended by NRC, this study fills the knowledge gap at the regional level of Atlanta airshed.

The first hypothesis tested in this study states that the probability of compliance by high emitters is zero. We do not expect to have total compliance nor total noncompliance, and rather expect that there are both compliant and non-compliant high emitters.

The study tests a second null hypothesis: The difference between the tailpipe emissions of non-compliant high emitting vehicles and normal emitting vehicles is not decreasing over time. In contrast, it is expected the difference between the tailpipe emissions of compliant high emitting vehicles and normal emitting vehicles is decreasing over time. This expectation is based on the assumption that compliant vehicle owners have carried out repairs on emission control systems of their vehicles according to IM program rules, while the non-compliant vehicle owners do not carry out the repairs.

Finally, third null hypothesis states: Conditional upon similar vehicular characteristics and atmospheric and physical conditions, the difference between tailpipe emissions of compliant and non-compliant high emitting vehicles is not significantly different from zero. We do not expect the third null hypothesis to be rejected because vehicular characteristics and atmospheric and physical conditions are expected to account for major variation in vehicular tailpipe emissions. 


\section{3: The decision model with perfect information}

Von Neumann and Morgenstern (1944), Raiffa (1968), Brown et al. (1974), Holloway (1979), and Winterfeldt and Edwards (1986) have developed the technique of decision trees to analyze the decisions under uncertainty and to suggest normative recommendations to the decision maker regarding what s/he should do in the face of a given decision problem. Decisions are uncertain because "the outcome of a decision often depends not only on the option chosen but also on the external events not under the decision maker’s control (Winterfeldt and Edwards 1986: 63).

A generalized one-stage decision tree represents $n$ possible actions available to the decision maker. Each action $a_{i}($ for $i=1, \ldots, n)$ entails events $e_{i j}\left(\right.$ for $\left.j=1, \ldots, m_{i}\right)$ with a probability $P\left(e_{i j}\right)$, such that $\sum_{j=1}^{m i} P\left(e_{i j}\right)=1$. Each action $a_{i}$ entailing event $e_{i j}$ results in an outcome $x_{i j}$. The most commonly employed dominance decision rule has the decision maker choosing an action $a_{i}$ that maximizes Expected Value $(\mathrm{EV})^{\mathrm{ii}}$ as:

$$
E V\left(a_{i}\right)=\sum_{j=1}^{m i} P\left(e_{i j}\right) x_{i j}
$$

Let $a_{i}{ }^{*}$ indicate the action in that stage that maximizes $E V$.

A multi-stage decision tree can be generalized from the one-stage model. With $n_{i}$ actions available in any stage $i$ (out of $L$ total stages), denote each available action as $a_{i j}$, where $j=1, \ldots n_{i}$. Let there be $m_{i j}$ possible events $e_{i j k}$ following each action $a_{i j}$, where $k=1, \ldots, m_{i j}$. By construction, $\sum_{k=1}{ }^{m i j} P\left(e_{i j k}\right)=1$. The final events $e_{L j k}$ have outcomes $x_{L j k}$ associated with them. The decision-maker's problem can be solved recursively, where

\footnotetext{
${ }^{\text {ii }}$ In the case that we replace the scalar outcomes $x_{i j}$ with a utility function $u\left(x_{i j}\right)$, the dominance decision rule states that the decision-maker should choose the action that maximizes Expected Utility (EU). Savage (1954) and Harsanyi (1967) proposed replacing EU with Subjective Expected Utility (SEU), which allows use of Bayesian probability theory to implement the dominance decision rule. In addition to dominance decision rule, other decision rules, such as Min-Max or Max-Min, can also be employed by a decision maker to solve a decision problem under uncertain future states.
} 
$a_{i j}{ }^{*}$ in any stage $i$ is chosen conditional upon choosing the optimal $a_{i+1, j}{ }^{*}, a_{i+2, j}$, and so forth until $a_{L j}{ }^{*}$. For an $L$-stage decision problem, this decision problem reduces to choosing $\mathrm{a}^{*}=\left\{a_{1}{ }^{*}, \ldots, a_{L}{ }^{*}\right\}$ to maximize:

$$
E V(a)=\sum_{i=1}^{L} E V\left(a_{i}\right)=\sum_{i=1}^{L} \sum_{j=1}^{n i} \sum_{k=1}^{m i j} P\left(e_{i j k}\right) x_{i j k}
$$

Figure 2 depicts the structure of a two-stage decision tree from the perspective of the regulated vehicle owners in the Atlanta airshed. ${ }^{\mathrm{iii}}$ The IM program in the Atlanta Airshed relies on the regulatory punishment strategy of denying the vehicle registration inside the 13 county program areas to vehicle owners whose vehicles do not pass the IM test. This regulatory punishment strategy sets up an incentive for the high emitters, which is one possible mechanism out of many others to attain the policy goal of reducing vehicular emissions. Given this incentive mechanism of regulatory punishment, it is the voluntary decision of high emitters either to pursue a compliant strategy and carry out actual repairs on the emission control systems of their vehicles or to pursue one of the following non-compliant strategies: pre-test or post-test fraudulent repairs, false IM passes through connivance with the management of the IM program testing stations, registering their vehicles inside the program boundaries without passing the IM test by bribing the vehicle registration authorities, avoiding the vehicle registration altogether, or by registering the vehicles outside the program area through "wash sales"iv or "pseudo addresses” and continuing to drive the vehicle inside the 13-county area. High emitters

\footnotetext{
iii Though the decision game continues for failed vehicles beyond the stage 2 , the addition of stage 3 really complicates the decision tree but does not substantially change the analysis. In other words, stage 2 may be taken as sum of all the stages occurring after the stage 2 .

iv Through a "wash sale", a vehicle owner retains the use of the vehicle inside the IM program boundaries even after selling and/or re-registering it outside. This is contrasted with a "real sale", when a vehicle owner truly sells the vehicle outside the program boundaries to a new owner.
} 
also have the choice of scrapping or selling/replacing their vehicles and thus choosing to “exit” from the decision game.

Assuming that program evaluators have perfect information about the actions taken by each vehicle owner, the decision paths in the decision tree can be used to estimate the "true" high emitter compliance rate. Translating the decision tree of the Figure 2 in tabular form, Table 1 lists all the possible 39 paths of actions and events, one of which must be followed by an IM test eligible vehicle owner in the Atlanta airshed. Table 1 identifies which of the each 39 paths are control, compliant, non-compliant or exit in the decision game presented in Figure 2. Suppose, $\mathrm{X}_{\mathrm{ijkl}}$ represents the total number of players who pursue any of the 39 decision paths resulting in outcomes $\mathrm{x}_{\mathrm{ijkl}}$, as shown in Figure 2 and described in Table 1, then the probability of high emitters complying can be defined by equation 3, which is essentially the total number of compliant high emitters divided by the total number of both compliant and non-compliant high emitters in the decision game:

$$
\begin{aligned}
& \operatorname{Pr}[\text { High emitter Compliance }]=\left[X_{1211}+X_{21}+X_{2211}+X_{3211}\right] /\left[X_{1211}+X_{21}+X_{2211}\right. \\
& +X_{3211}+X_{1212}+X_{1221}+X_{1222}+X_{123}+X_{124}+X_{1251}+X_{1252}+X_{126}+X_{2212}+X_{2221}+ \\
& X_{2222}+X_{223}+X_{224}+X_{2251}+X_{2252}+X_{226}+X_{31}+X_{3212}+X_{3222}+X_{323}+X_{324}+X_{3251}+ \\
& \left.X_{3252}+X_{326}+X_{4}+X_{5}+X_{61}+X_{62}+X_{7}\right]
\end{aligned}
$$

Similarly, the probability of overall compliance can be estimated by a ratio of compliant to both compliant and non-compliant vehicle owners, as shown in equation 4:

$$
\begin{array}{r}
\operatorname{Pr} \text { [Overall Compliance] }=\left[X_{11}+X_{1211}+X_{21}+X_{2211}+X_{3211}\right] /\left[X_{11}+X_{1211}+\right. \\
X_{21}+X_{2211}+X_{3211}+X_{1212}+X_{1221}+X_{1222}+X_{123}+X_{124}+X_{1251}+X_{1252}+X_{126}+X_{2212}+
\end{array}
$$




$$
\begin{aligned}
& X_{2221}+X_{2222}+X_{223}+X_{224}+X_{2251}+X_{2252}+X_{226}+X_{31}+X_{3212}+X_{3222}+X_{323}+X_{324}+ \\
& \left.X_{3251}+X_{3252}+X_{326}+X_{4}+X_{5}+X_{61}+X_{62}+X_{7}\right]
\end{aligned}
$$

\section{4: A decision model with imperfect information ${ }^{\mathrm{v}}$}

The program designers cannot have the perfect information needed to ascertain precisely how many high emitters will pursue compliant and non-compliant strategies. Previous researchers have employed the methodology of collecting the data about vehicle owners' actions through randomly testing the vehicles by road-side pullovers; but this methodology has proven to be overwhelmingly cost-ineffective and time-consuming (EPA 2002). The IM program data cannot capture all the non-compliant strategies listed in Figure 2. Although the remote sensing data cannot provide perfect information about each of the compliant and non-compliant paths listed in Table 1 and Figure 2, this provides the best available information because it lets us track some compliant and noncompliant actions of high emitters as compared to the IM program data or road-side pullover data alone. It should, however, be noted that remote sensing data cannot provide perfect information about compliant and non-compliant actions. Before discussing informational limitations that arise due to the use of remote sensing data, we explain how remote sensing data enables measuring compliant and non-compliant strategies of high emitters.

As shown in Figure 3, the remote sensing sample of on-road data containing observations of vehicles found registered in the state of Georgia is subdivided further into two fleets. The IM-eligible fleet contains vehicles that were required under the rules of

\footnotetext{
${ }^{\mathrm{v}}$ A decision model with imperfect information does not imply here informational limitations of vehicle owners. Rather, imperfect information here refers to the limited information available to policy makers, program regulators or evaluators about the compliance behavior of vehicle owners.
} 
the IM program to take an IM test, and the IM-ineligible fleet contains other vehicles. The eligibility criteria reflect the rules of the IM program for each evaluation year, such as gasoline-powered cars and light-duty trucks under GVWR 8000 lbs between 3 to 25 years old with odd model years were required to be tested in 1999, and even model years in $2000 .^{\text {vi }}$

The eligible fleet contains vehicles of two additional kinds: Vehicles that were exempted from IM test and vehicles that were not exempted from IM test, which is checked by tracking the eligible fleet vehicles in the exemption data. The non-exempted eligible fleet of vehicles of the on-road sample is tracked in the IM program data using the variables: vehicle identification number (VIN) and model year. The vehicles found in the IM program data are further sub-divided into three fleets: control fleet if the vehicle passed the initial IM test, retest-pass fleet if the vehicle failed the initial test but passed the re-test, and retest-fail fleet if the vehicle failed the initial test and again failed the retest or did not re-appear in the IM test.

The eligible-fleet vehicles not found in the IM data of the evaluation year contain vehicles of three further kinds: first, vehicles that were found in the previous IM cycle and failed an initial test. These vehicles belong to the "missing failed" fleet, as they are found registered inside the IM program boundaries without passing the IM test in the year of evaluation, but they failed the initial test in the previous IM cycle. Second, similarly, the missing IM-eligible vehicles that passed the initial test in the previous IM cycle are classified as belonging to the "missing passed" fleet. Third, the IM-eligible missing vehicles that were not found in either the current or previous IM cycle are categorized as

\footnotetext{
${ }^{\text {vi }}$ Detailed IM program rules can be found at http://www.cleanairforce.com/ and at EPA's website http://www.epa.gov/oms/epg/progeval.htm. Some major rules are also discussed in chapter 4 in Zia (2004).
} 
the "missing fleet." These missing fleet vehicles potentially indicate the error rate in VIN and model year variables as well as reporting error in IM, registration, and remote sensing databases.

From the set of unique valid vehicles that were designated as non-eligible vehicles, two further sub-fleets are defined. The first sub-fleet includes vehicles that are registered inside the 13-county area but are not eligible to appear in the IM test as per IM program rules. This fleet is designated as the IM-ineligible fleet inside the 13-county area for that particular evaluation year. It is noteworthy that under the biennial IM testing program, the ineligible fleet contains vehicles that underwent testing in the previous year. The second sub-fleet includes vehicles that are registered in the state of Georgia outside the 13-county IM program boundaries.

The rest of Georgia fleet outside the 13-county area is further subdivided into three fleets. First, the "migrated failed" fleet includes vehicles that are found to have failed an initial IM test in the previous IM cycle. This category of vehicles represents those high-emitting vehicles that appear to have migrated outside the IM boundaries but are still being driven inside the IM boundaries. Second, the "migrated passed" fleet includes vehicles that are found to have passed an initial IM test in the previous IM cycle. Third, the "rest of the Georgia" fleet includes vehicles that have no record in the previous IM cycle.

In summary, as the bold-faced terminal nodes in figure 3 indicate, the sample of the on-road remote sensing data that is selected to evaluate the IM program for a given year is subdivided into 11 vehicle fleets: control [Q $\mathrm{Q}_{1}$, IM ineligible inside the 13-county area $\left[\mathrm{Q}_{2}\right]$, waived $\left[\mathrm{Q}_{3}\right]$, rest of the Georgia fleet $\left[\mathrm{Q}_{4}\right]$, missing $\left[\mathrm{Q}_{5}\right]$, retest-pass $\left[\mathrm{Q}_{6}\right]$, 
migrated-passed $\left[\mathrm{Q}_{7}\right]$, retest-fail $\left[\mathrm{Q}_{8}\right]$, migrated-failed $\left[\mathrm{Q}_{9}\right]$, missing-failed $\left[\mathrm{Q}_{10}\right]$, and missing-passed $\left[\mathrm{Q}_{11}\right]$. These eleven fleet types are coded as eleven binary variables ( $\sum_{\mathrm{q}=1}{ }^{11} \mathrm{Q}_{\mathrm{q}}=1$ ), such as the variable "retest pass" $\left[\mathrm{Q}_{6}\right]$ is valued 1 if the vehicle belongs to the retest-pass fleet and 0 otherwise, and so on. Vehicles belonging to retest-pass and migrated-passed fleets are characterized as belonging to compliant vehicle owners because they duly passed the IM test. On the other hand, vehicles belonging to retestfail, missing-fail, migrated-failed and missing-passed fleets are characterized as belonging to non-compliant vehicle owners because these vehicles are observed inside the IM program boundaries without having passed the emissions test.

Classifying a vehicle as a high emitter after it fails the initial IM test as per IM emission cut-point rules implies the probability of high emitter compliance is the ratio of the compliant high emitters to the total high emitters. Conversely, the probability of high emitter non-compliance is equal to 1 minus the probability of high emitter compliance. Formally:

$$
\operatorname{Pr}[\text { High Emitter Compliance }]=\left[Q_{6}+Q_{7}\right] /\left[Q_{6}+Q_{7}+Q_{8}+Q_{9}+Q_{10}+Q_{11}\right]
$$

Similarly, the probability of overall compliance is measured by taking a ratio of the compliant to both compliant and non-compliant IM eligible vehicles, as shown in equation 6:

$\operatorname{Pr}[$ Overall Compliance $]=\left[Q_{1}+Q_{6}+Q_{7}\right] /\left[Q_{1}+Q_{6}+Q_{7}+Q_{8}+Q_{9}+Q_{10}+Q_{11}\right]$

The empirical methodology to estimate probability of compliance, as described in equations 5 and 6 , has the following limitations relative to an estimate using perfect information as in equations 3 and 4: (1) The probability of high emitter compliance is over-estimated because one cannot find those high emitters that simply avoid registration 
of their vehicles inside the state of Georgia and continue to drive them inside the IM program boundaries without valid license plates. (2) The probability of high emitter compliance is also over-estimated because the imperfect information methodology cannot single out those vehicle owners who register their vehicles out of Georgia state (through a wash sale) and still drive inside the program area (note that path 10, 21, 32 and 38 in Table 1 are only partially captured). (3) The probability of high emitter compliance is under-estimated because the methodology cannot separate the high emitters who do pretest actual repairs and pass the initial test (path 12 in Table 1) from the normal emitters who pass their initial test without any actual repairs (path 1 in Table 1). (4) The probability of high emitter compliance is over-estimated because the methodology cannot single out those non-compliant high emitters who fraudulently passed the initial IM test (path 23 in Table 1).

(5) The migrated-pass group of vehicle owners may be acting preemptively to avoid the IM program by registering their vehicles outside the IM program area, but they cannot be discerned from those vehicle owners who actually sold their vehicles outside the program. This results in under-estimation of high emitter compliance rates. (6) The missing-pass group of vehicle owners includes those who sold their vehicles after passing the IM test to other vehicle owners inside the IM program area (which may cause them to avoid the IM test according to IM rules), for which reason not all of them can be classified as non-compliant types. On the other hand, the missing-pass group, by definition, is a non-compliant type, because as per IM rules they were eligible to appear in the IM test, but their VIN records are not found in the IM data of the evaluation year. This results in under-estimation of the percent high-emitter compliance. (7) Both IM and 
remote sensing data methodologies contain the possibility of a matching error due to the incorrectly reported VIN and model year variables. This matching error is probably represented in the category of "missing-fleet” vehicles, but this is not certain.

Given these seven serious limitations that arise due to the imperfect information, utmost caution is needed to interpret the statistics that reduce 11 fleet types to 3: control, compliant, and non-compliant. Due to these limitations, the empirical results for all eleven fleet kinds are reported.

\section{5: The data}

We used on-road vehicle emissions remote sensing data (1997-2001) collected by Air Quality Laboratory (AQL), IM program and exemption data (1997-2001) provided by the Georgia Department of Natural Resources (GA-DNR), Vehicle registration data (1997-2002) provided by the Georgia Department of Motor Vehicles and Safety (GADMVS), and climate data (1997-2001) released by the National Climatic Data Center. Table 2 shows descriptive statistics of the mixed-pool remotely sensed sample data collected between 1997 and 2001.

The sample data has a total of 777,408 observations, $85.9 \%$ of which are unique vehicles $^{\text {vii }}$. Of the total sample, 109,249 (14.1\%) in the sample are vehicles observed at

vii The raw remote sensing data between 1997 and 2001, collected by AQL, contains a total of 1.42 million observations measured at various years, times, and locations in the Atlanta MSA. In the initial datacleaning process of the raw data, we dropped the observations from the sample for which either the license plates were not clearly readable from the pictures of the license plates taken by the remote sensors, or the license plates that did not match Georgia's vehicle registration databases. Further, if a vehicle was observed multiple times during a year, its last observation in the sample was retained. This way, the sample is reduced to observations on "unique" vehicles during a calendar year, which facilitates its tracking in IM program data. 
least twice, 17,320 (2.2\%) are observed at least three times, and 2,631 (0.3\%) are observed at least four times in different calendar years between 1997 and 2001.

Figure 4 shows 73 remote sensing sites that were used to collect the sample data between 1997 and 2001. This figure shows that the sample remote sensing data has been collected inside the 13 IM program counties during the five years of the study period. Figure 4 also shows percentage of observations as a part of total sample collected at each remote sensing site from 1997 to 2001. Table 2 shows that the mean age of the vehicles in the sample is 5.4 years. It is noteworthy that both compliant and non-compliant vehicles belong in all vehicle age groups, not just older vehicles. Sixty-two percent of the total sample contains passenger cars, while the remaining 38\% contains trucks, vans, mini-vans and SUVs, etc.

Figure 5 shows vehicular tailpipe emissions distributed by vehicle age and observation year. This figure reveals that $\mathrm{CO}, \mathrm{HC}$ and $\mathrm{NO}$ emissions are an increasing function of vehicle age, and as vehicle age increases above 14 years, the standard deviation also increases. Further, $\mathrm{CO}$ and $\mathrm{HC}$ emissions are decreasing over time from 1997 to 2001, while NO emissions appear to be nondecreasing. Note that NO emissions were not measured before 1999.

Figure 6 shows the annual trend of CO, HC and NO emission factors by 11 fleet types during the study period 1997 to 2001. While CO, HC and NO emission factors have decreased from 1997 to 2001, the vehicles in the five experimental fleets - retestpass, migrated-pass, retest-fail, migrated-fail, and missing-fail - continue to emit higher $\mathrm{CO}, \mathrm{HC}$ and $\mathrm{NO}$ emissions than the control group vehicles. Only the missing-passed fleet of vehicles emits similar emissions as the control group vehicles. Vehicles in the 
ineligible fleet are also similar to the control group, but the waived group vehicles emit, on average, higher emissions than the control group vehicles. Table 2 also shows that HC, CO and NO emissions are heavily skewed (in decreasing order).

\section{6: Methodology to estimate the emission impact of compliant and non-compliant behavioral actions of high emitters}

Multiple statistical decision theory models, employing mixed-pooled time series multivariate generalized linear and non-linear regressions, are used to test hypotheses concerning the impacts on vehicular emissions due to the compliant and non-compliant behaviors of high emitters, after controlling for technological, vehicular, physical and temporal parameters. The following linear equation was initially specified to quantify the impact of compliant and non-compliant behaviors on the vehicular tailpipe emissions:

$$
\begin{gathered}
Y_{P}=\alpha_{0}+\sum_{q=2}^{11} \beta_{q} Q_{q}+\sum_{r=1}{ }^{29} \gamma_{r} R_{r}+\sum_{s=1}{ }^{7} \phi_{s} S_{s}+\sum_{t=2}^{5} \delta_{t} T_{t}+\sum_{t=2}^{5} \sum_{q=2}{ }^{11} \Delta_{t q} T_{t} Q_{q}+\varepsilon_{I}, \text { for } \\
P=[C O, H C, N O]
\end{gathered}
$$

Where $Y_{P}$ variables show $\mathrm{CO}, \mathrm{HC}$ and $\mathrm{NO}$ emission factors in grams per gallon, $Q_{q}$ variables show the 10 fleet types. The control fleet is the reference group in $\mathrm{Q}_{\mathrm{q}}$ variables. $\mathrm{R}_{\mathrm{r}}$ variables show vehicular characteristics including their emission control technological systems. A Ford car made in the USA of zero years of age is the reference group in $\mathrm{R}_{\mathrm{r}}$ variables. ${ }^{\text {viii }} \mathrm{S}_{\mathrm{s}}$ variables show the physical and atmospheric contextual conditions at the time of remote sensing measurements, and $\mathrm{T}_{\mathrm{t}}$ variables show the observation year. 1997 is the base year in $T_{t}$ variables. The interaction terms ( $\mathrm{T} x \mathrm{Q}$ ) track over time the changes

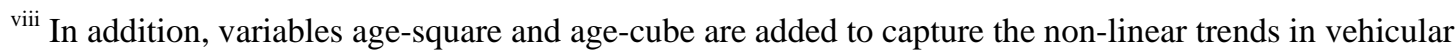
tailpipe emissions as a function of vehicle age.
} 
in the emission factors of the 11 fleet types during the study period. Column 2 in table 2 shows the relevant symbol for each individual variable shown in equation 7.

Since evidence for heteroskedasticity is found in the data, as well as non-normal distributions of vehicular emissions are observed in sample statistics, an attempt was first made to correctly specify the functional form of the models -- such as through Box-Cox regressions.

In order to estimate the non-linearities in the functional form between the dependent and the independent variables, best non-linear fits for the dependent variables were estimated. More specifically, the following Box-Cox transformation parameter $(\lambda)$ was estimated by using the maximum likelihood estimation techniques:

$$
\begin{aligned}
& Y_{P}^{(\lambda)}= \alpha_{0}+\sum_{q=2}^{11} \beta_{q} Q_{q}+\sum_{r=1}^{29} \gamma_{r} R_{r}+\sum_{s=1}^{7} \phi_{s} S_{s}+\sum_{t=2}^{5} \delta_{t} T_{t}+\sum_{t=2}^{5} \sum_{q=2}^{11} \Delta_{t q} T_{t} Q_{q}+\varepsilon_{I} \\
& \text { for } P=[C O, H C, N O]
\end{aligned}
$$

where $\varepsilon_{I} \sim \mathrm{N}\left(0, \sigma^{2}\right)$ and the dependent variables $Y_{P}[$ for $P=C O, H C$ or $N O$ ] are subject to a Box-Cox transformation with parameter $\lambda$. The estimated value of the parameter $\lambda$ guides the researcher to approximately estimate the non-linearities through transformed values of dependent variables in the Generalized Linear Models (GLMs). Specifically, as discussed by Davidson and MacKinnon (1993), a linear form of dependent variable is retained if $\lambda$ is (approximately) equal to 1 , a logarithmic transformation of the dependent variable is carried out if $\lambda$ is (approximately) equal to 0 , and an inverse multiplicative transformation of the dependent variable is carried out if $\lambda$ is (approximately) equal to -1 . The Box-Cox regression results (shown in Zia 2004) suggested that the log-linear models be run for $\mathrm{CO}, \mathrm{HC}$ and $\mathrm{NO}$ by transforming the dependent variables into their natural logarithm equivalents. 
Heteroskedasticity in the log-linear models was corrected by employing multiple methodologies. First, heteroskedasticity was corrected by using White’s (1980) robust variance estimator methods. Second, a weighted ${ }^{\text {ix }}$ least squares (WLS) regression model was used to generate more efficient standard errors and correct for heteroskedasticity.

Results from five regression models - the linear OLS with the robust errors model, Box-Cox regression model, the log-linear with robust errors model, the log-linear weighted least squares (WLS) model and the log-linear robust regression model - for predicting CO, HC and NO emissions are reported in Zia (2004). Since WLS log-linear model presents the parametric values with most efficient standard errors after correcting for heteroskedasticity (as well as the highest $\mathrm{R}^{2}$ values), only results from WLS models are reported in this paper.

\section{7: Results}

\section{1: Probability of high emitter compliance and non-compliance}

Table 3 presents the probability of high emitter compliance in each of the five years of study, as computed following equation 5. These results should be strictly interpreted in the light of limitations extensively discussed in section 4 . Overall, $41.2 \%$ of the high emitters in the total sample appear to be compliant, and, conversely, $58.8 \%$ appear to be non-compliant. Except for the base year of 1997, the probability of high emitter compliance is between $36.6 \%$ and $41 \%$ during the period 1998 to 2001 . $^{\mathrm{x}}$ The null

\footnotetext{
${ }^{\text {ix }}$ Weights in WLS regression model are generated by regressing a natural log of squared Studentized residuals of OLS regression on independent variables in equation 7.

${ }^{x}$ The 1997 result, which shows probability of high emitter compliance at 83.7\%, is an outlier in the temporal trend because no vehicles in the 1997 remote sensing sample were found in four treatment fleets: migrated pass, migrated fail, missing fail, missing pass. 1997 is an exception because it was the first year of the "enhanced" IM program encompassing 13 counties. No vehicles in these four fleets were matched with
} 
hypothesis that the probability of high emitter compliance is zero is rejected. Also, the probability of high emitter compliance is not unity, which means that the regulatory objective of IM program is not being fully met. Overall compliance rate stands at $88.8 \%$.

\section{2: The impact of high emitter compliant and non-compliant actions on vehicular tailpipe emissions}

The impact of high emitter compliance and non-compliance on vehicular emissions in the Atlanta airshed between 1997 and 2001 is estimated by the empirical measurement of equation 7, as adjusted for non-linearities and heteroskedasticity. Table 4 presents the predicted parametric values for equation 7 when $\mathrm{CO}, \mathrm{HC}$ and NO (in grams/gallon) are regressed. This table shows the predictors for WLS log-linear model. Coefficient values represent ceteris paribus percent changes in the dependent variable for one-unit change in the independent parameters.

\subsection{1: Impacts on CO emissions}

The WLS model coefficients on time variables in column 2 of Table 4 predict that control group vehicles emitted 18\%, 42\%, 48\% and 66\% less emissions in 1998, 1999, 2000, and 2001, respectively, than their 1997 levels on average. Given this temporal trend of decreasing CO emission factors between 1997 and 2001, the ceteris paribus effect of compliant and non-compliant strategies of high emitters on CO emission factors can be analyzed by a deeper scrutiny of coefficients on 10 decision variables and 36 interaction terms.

\footnotetext{
"basic" IM program data that was collected in the four counties of Atlanta in 1995 and 1996. Figure 4 shows 4 and 13 counties covered respectively under basic and enhanced IM program.
} 
Of the two compliant fleets, the retest-pass fleet vehicles are predicted to emit 34\% more CO emissions than the control fleet vehicles in 1997. From 1998 to 2001, the difference between retest-pass and control group vehicular emissions did not significantly change from their 1997 level difference of 34\%. Only in 2000, the difference changed such that retest-pass vehicles emitted only $23 \%$ more than control group vehicles.

The second compliant fleet type, referred to as the migrated-pass fleet, emitted $10 \%$ more CO emissions than the control fleet vehicles in 1998 . The $10 \%$ difference between migrated-pass and control group vehicles did not significantly change from 1999 to 2001.

Of the four non-compliant fleet vehicles, retest-fail vehicles are among the dirtiest CO high emitters in all five years of the study. In 1997, retest-fail vehicles are predicted to emit 38\% more CO emissions than the control fleet vehicles. In 1998 and 1999, the difference between retest-fail and control group vehicular $\mathrm{CO}$ emission factors significantly increased to $61 \%$ and $72 \%$ respectively. In 2000 and 2001, the difference between retest-fail and control group $\mathrm{CO}$ emission factors is statistically not different from their 1997 level difference of 38\%.

The second non-compliant fleet, containing migrated-fail vehicles, has also some of the dirtiest CO high emitters. From 1998 to 2001, migrated-fail vehicles, on average, emitted 55\% more CO than the control fleet vehicles.

The third non-compliant fleet, missing-fail fleet vehicles, are also significantly higher in CO emissions than the control fleet vehicles. In 1998, missing-fail fleet vehicles, on average, emitted 27\% more CO than the control fleet vehicles that year. This difference did not significantly decrease during 2000 to 2001. However, in 1999, the 
difference between missing-fail and control group vehicular CO emissions increased to $53 \%$.

The fourth non-compliant fleet, missing-pass vehicles did not produce significantly higher CO emissions than the control fleet vehicles in 1998 and 2000. In 1999, the missing-pass vehicles emitted 7\% more CO than control group vehicles. In 2001, however, the missing-pass vehicles emitted 10\% less CO than control group vehicles

An F-test was used to test the null hypothesis that, conditional on the same vehicular characteristics (R) and atmospheric conditions (S), the difference between the CO emissions of compliant and non-compliant vehicle fleets is zero. The null hypothesis could not be rejected. Thus, conditional on the same vehicular characteristics (R) under the same atmospheric conditions (S), there is no statistical difference between the CO emission factors if that vehicle was in the compliant or non-compliant fleet in the Atlanta airshed.

\subsection{2: Impacts on HC emissions}

The coefficients on time variables in column 3 of Table 4 indicate that vehicles emitted $16 \%$, 40\%, 57\% and 102\% less HC emissions in 1998, 1999, 2000, and 2001, respectively, than their average 1997 levels. Thus, overall, HC emissions drastically reduced from 1997 to 2001. On the other hand, the difference between HC emissions of treatment and control fleets either stayed the same or even increased from their 1997 difference level. More specifically, of the two apparently compliant fleets, retest-pass fleet vehicles were emitting $12 \%$ more $\mathrm{HC}$ emissions than the control fleet vehicles in 1997, and that difference did not significantly change for 1998, 1999 or 2000. In 2001, 
the HC emissions of retest-pass fleet vehicles were 50\% greater than the control fleet's. Migrated-pass vehicles emitted 10\% higher HC emission factors than the control fleet vehicles in 1998. That difference did not significantly change for 2000 and 2001, while it was eliminated for 1999.

The four non-compliant fleet vehicles were worse: the retest-fail vehicles emitted 12\% more HC emissions than the control fleet vehicles in 1997. In 1999, 2000, and 2001, one of the most important results of this study, the difference in the HC emission factors of retest-fail vehicles with the control fleet vehicles increased to $29 \%$, $33 \%$ and $52 \%$, respectively, above their $12 \%$ difference in 1997. Thus, given the temporal trend of decreasing $\mathrm{HC}$ emissions, the retest-fail vehicles are reducing $\mathrm{HC}$ emissions at a slower rate than control fleet vehicles. This result is important because it justifies targeting special efforts at chronically high-emitting vehicles.

The same applies to migrated-fail and missing-fail vehicles. In 2001, migratedfail vehicles, on average, emitted $60 \%$ higher $\mathrm{HC}$ emissions as compared to the control fleet vehicles that year. However, the difference between the HC emissions of the migrated-fail vehicles and the control fleet vehicles was 0\%, 9\%, and 33\% in 1998, 1999, and 2000. Similarly, the difference between the HC emissions of the missing-fail vehicles and the control fleet vehicles was 38\% higher in 2001 than the 1998 level (when there was no significant difference). The HC emissions from the migrated-fail and missing-fail vehicles are thus also reducing at a slower rate over time, given the temporal trend of decreasing $\mathrm{HC}$ emission factors for control group vehicles. The fourth non-compliant fleet, missing-pass vehicles, produced 4\% higher HC emissions than the control fleet vehicles in 1998, but this difference appears to have vanished by 2001. 
An F-test was employed to test the null hypothesis that, conditional on the same vehicular characteristics (R) and atmospheric conditions (S), the difference between the HC emissions of compliant and non-compliant vehicles is not different from zero. The null hypothesis is rejected, which suggests there is a statistical difference between the HC emission factors of compliant and non-compliant vehicles. The F-test suggests that compliant vehicle groups emitted less HC emissions as compared to non-compliant vehicle groups, even after controlling for vehicular characteristics and atmospheric conditions, during the study period in the Atlanta airshed.

\subsection{3: Impacts on NO emissions}

The vehicles emitted similar NO emissions in 2000 compared to average 1999 levels; but NO emissions decreased by $29 \%$ in 2001 . Of the two apparently compliant fleets, retest-pass fleet vehicles were emitting 36\% more NO emissions than the control fleet vehicles in 1999, with the difference rising (but statistically insignificantly) in 2000 and 2001. The difference in NO emissions of migrated-pass and control fleet vehicles was statistically insignificant in 1999, 2000 and 2001.

The three non-compliant vehicle groups - retest-fail, migrated-fail and missingfail - had no statistical difference in NO emissions from control group vehicles in 1999, 2000 and 2001. The fourth non-compliant fleet, missing-pass vehicles, produced $17 \%$ higher NO emissions than the control fleet vehicles in 1999. By 2001, however, the difference between NO emissions of missing-pass and control fleet vehicles decreased by $31 \%$, such that missing-pass vehicles emitted $14 \%$ less NO than control group vehicles on average. 
An F-test was employed to test the null hypothesis that, conditional on the same vehicular characteristics (R) and atmospheric conditions (S), the difference between the NO emissions of compliant and non-compliant vehicle fleets is not significantly different from zero. As expected, the null hypothesis was not rejected so there is no statistical difference between NO emission factors of compliant and non-compliant vehicles during the period 1999 to 2001, conditional on vehicular characteristics (R), atmospheric conditions (S), and time (T).

\section{8: Conclusions}

The high emitters affected by regulatory environmental policy interventions are neither perfectly compliant nor non-compliant. In a case-study of IM program intervention in the Atlanta airshed, it is found that about $37 \%$ to $41 \%$ of the high emitters comply, while the other $59 \%$ to $63 \%$ do not comply and attempt to free ride on the common resource of clean air.

After controlling for vehicle age, type, manufacturer, technology, atmospheric and physical conditions and time, there is no statistical difference in the vehicular tailpipe $\mathrm{CO}$ and NO emissions produced by high emitters in compliant and non-compliant groups. However, vehicles in compliant groups emit less HC emissions as compared to the vehicles in non-compliant groups. The $\mathrm{CO}, \mathrm{HC}$ and $\mathrm{NO}$ emissions have significantly decreased over time for normal emitting vehicles. However, the difference between CO, $\mathrm{HC}$ and $\mathrm{NO}$ emissions of high-emitting fleets and normal-emitting fleets has not significantly decreased over time. 
The challenges posed by the findings of this study can be tackled through several policy options, prioritization of which will require a complete policy analysis with a much deeper institutional content. Policymakers can use the results of this paper in three important ways: (1) assess the determinants of $\mathrm{CO}, \mathrm{HC}$ and $\mathrm{NO}$ emissions by vehicular characteristics, atmospheric and physical conditions and compliance behaviors of vehicle owners; (2) assess whether there are important un-observables about a car that are correlated with compliance status that might affect emissions (and it appears that they do for $\mathrm{HC}$ but not $\mathrm{CO}$ or $\mathrm{NO}$ ); and (3) assess the emission reduction effectiveness of an IM program over time in a major ozone non-attainment region.

\section{Acknowledgments}

The authors are thankful to Air Quality Laboratory for providing remote sensing data, Georgia Department of Natural Resources and Georgia Environmental Protection Division for IM program data and Georgia Department of Motor Vehicles and Safety for the vehicle registration data. Part of the work was undertaken under grants from Georgia Department of Natural Resources and Environmental Protection Agency, for which the authors are very grateful. 
Tables

Table 1: Possible decision paths, one of which must be followed by a vehicle owner in response to IM program

\begin{tabular}{|c|c|c|c|c|}
\hline No. & Decision Path & Nature of Path & Outcome & Observed \\
\hline 1 & $\mathrm{a}_{1} \rightarrow \mathrm{e}_{11}$ & Control & $\mathrm{X}_{11}$ & Yes \\
\hline 2 & $\mathrm{a}_{1} \rightarrow \mathrm{e}_{12} \rightarrow \mathrm{b}_{121} \rightarrow \mathrm{f}_{1211}$ & Compliant & $\mathrm{X}_{1211}$ & Yes \\
\hline 3 & $\mathrm{a}_{1} \rightarrow \mathrm{e}_{12} \rightarrow \mathrm{b}_{121} \rightarrow \mathrm{f}_{1212}$ & Non-compliant & $\mathrm{X}_{1212}$ & Yes \\
\hline 4 & $\mathrm{a}_{1} \rightarrow \mathrm{e}_{12} \rightarrow \mathrm{b}_{122} \rightarrow \mathrm{f}_{1221}$ & Non-compliant & $\mathrm{X}_{1221}$ & Yes \\
\hline 5 & $\mathrm{a}_{1} \rightarrow \mathrm{e}_{12} \rightarrow \mathrm{b}_{122} \rightarrow \mathrm{f}_{1222}$ & Non-compliant & $\mathrm{X}_{1222}$ & Yes \\
\hline 6 & $\mathrm{a}_{1} \rightarrow \mathrm{e}_{12} \rightarrow \mathrm{b}_{123}$ & Non-compliant & $\mathrm{X}_{123}$ & Yes \\
\hline 7 & $\mathrm{a}_{1} \rightarrow \mathrm{e}_{12} \rightarrow \mathrm{b}_{124}$ & Non-compliant & $\mathrm{X}_{124}$ & Yes \\
\hline 8 & $\mathrm{a}_{1} \rightarrow \mathrm{e}_{12} \rightarrow \mathrm{b}_{125} \rightarrow \mathrm{f}_{1251}$ & Non-compliant & $\mathrm{X}_{1251}$ & No \\
\hline 9 & $\mathrm{a}_{1} \rightarrow \mathrm{e}_{12} \rightarrow \mathrm{b}_{125} \rightarrow \mathrm{f}_{1252}$ & Non-compliant & $\mathrm{X}_{1252}$ & No \\
\hline 10 & $\mathrm{a}_{1} \rightarrow \mathrm{e}_{12} \rightarrow \mathrm{b}_{126}$ & Non-compliant & $\mathrm{X}_{126}$ & Yes* \\
\hline 11 & $\mathrm{a}_{1} \rightarrow \mathrm{e}_{12} \rightarrow \mathrm{b}_{127}$ & Exit & $\mathrm{X}_{127}$ & Yes \\
\hline 12 & $\mathrm{a}_{2} \rightarrow \mathrm{e}_{21}$ & Compliant & $\mathrm{X}_{21}$ & Yes \\
\hline 13 & $\mathrm{a}_{2} \rightarrow \mathrm{e}_{22} \rightarrow \mathrm{b}_{221} \rightarrow \mathrm{f}_{2211}$ & Compliant & $\mathrm{X}_{2211}$ & Yes \\
\hline 14 & $\mathrm{a}_{2} \rightarrow \mathrm{e}_{22} \rightarrow \mathrm{b}_{221} \rightarrow \mathrm{f}_{2212}$ & Non-compliant & $\mathrm{X}_{2212}$ & Yes \\
\hline 15 & $\mathrm{a}_{2} \rightarrow \mathrm{e}_{22} \rightarrow \mathrm{b}_{222} \rightarrow \mathrm{f}_{2221}$ & Non-compliant & $\mathrm{X}_{2221}$ & Yes \\
\hline 16 & $\mathrm{a}_{2} \rightarrow \mathrm{e}_{22} \rightarrow \mathrm{b}_{222} \rightarrow \mathrm{f}_{2222}$ & Non-compliant & $\mathrm{X}_{2222}$ & Yes \\
\hline 17 & $\mathrm{a}_{2} \rightarrow \mathrm{e}_{22} \rightarrow \mathrm{b}_{223}$ & Non-compliant & $\mathrm{X}_{223}$ & Yes \\
\hline 18 & $\mathrm{a}_{2} \rightarrow \mathrm{e}_{22} \rightarrow \mathrm{b}_{224}$ & Non-compliant & $\mathrm{X}_{224}$ & Yes \\
\hline 19 & $\mathrm{a}_{2} \rightarrow \mathrm{e}_{22} \rightarrow \mathrm{b}_{225} \rightarrow \mathrm{f}_{2251}$ & Non-compliant & $\mathrm{X}_{2251}$ & No \\
\hline 20 & $\mathrm{a}_{2} \rightarrow \mathrm{e}_{22} \rightarrow \mathrm{b}_{225} \rightarrow \mathrm{f}_{2252}$ & Non-compliant & $\mathrm{X}_{2252}$ & No \\
\hline 21 & $\mathrm{a}_{2} \rightarrow \mathrm{e}_{22} \rightarrow \mathrm{b}_{226}$ & Non-compliant & $\mathrm{X}_{226}$ & Yes* \\
\hline 22 & $\mathrm{a}_{2} \rightarrow \mathrm{e}_{22} \rightarrow \mathrm{b}_{227}$ & Exit & $\mathrm{X}_{227}$ & Yes \\
\hline 23 & $\mathrm{a}_{3} \rightarrow \mathrm{e}_{31}$ & Non-compliant & $\mathrm{X}_{31}$ & Yes \\
\hline 24 & $\mathrm{a}_{3} \rightarrow \mathrm{e}_{32} \rightarrow \mathrm{b}_{321} \rightarrow \mathrm{f}_{3211}$ & Compliant & $\mathrm{X}_{3211}$ & Yes \\
\hline 25 & $\mathrm{a}_{3} \rightarrow \mathrm{e}_{32} \rightarrow \mathrm{b}_{321} \rightarrow \mathrm{f}_{3212}$ & Non-compliant & $\mathrm{X}_{3212}$ & Yes \\
\hline 26 & $\mathrm{a}_{3} \rightarrow \mathrm{e}_{32} \rightarrow \mathrm{b}_{322} \rightarrow \mathrm{f}_{3221}$ & Non-compliant & $\mathrm{X}_{3221}$ & Yes \\
\hline 27 & $\mathrm{a}_{3} \rightarrow \mathrm{e}_{32} \rightarrow \mathrm{b}_{322} \rightarrow \mathrm{f}_{3222}$ & Non-compliant & $\mathrm{X}_{3222}$ & Yes \\
\hline 28 & $\mathrm{a}_{3} \rightarrow \mathrm{e}_{32} \rightarrow \mathrm{b}_{323}$ & Non-compliant & $\mathrm{X}_{323}$ & Yes \\
\hline 29 & $a_{3} \rightarrow e_{32} \rightarrow b_{324}$ & Non-compliant & $\mathrm{x}_{324}$ & Yes \\
\hline 30 & $\mathrm{a}_{3} \rightarrow \mathrm{e}_{32} \rightarrow \mathrm{b}_{325} \rightarrow \mathrm{f}_{3251}$ & Non-compliant & $\mathrm{X}_{3251}$ & No \\
\hline 31 & $\mathrm{a}_{3} \rightarrow \mathrm{e}_{32} \rightarrow \mathrm{b}_{325} \rightarrow \mathrm{f}_{3252}$ & Non-compliant & $\mathrm{X}_{3252}$ & No \\
\hline 32 & $\mathrm{a}_{3} \rightarrow \mathrm{e}_{32} \rightarrow \mathrm{b}_{326}$ & Non-compliant & $\mathrm{X}_{326}$ & Yes* \\
\hline 33 & $a_{3} \rightarrow e_{32} \rightarrow b_{327}$ & Exit & $\mathrm{X}_{327}$ & Yes \\
\hline 34 & $\mathrm{a}_{4}$ & Non-compliant & $\mathrm{x}_{4}$ & Yes \\
\hline 35 & $\mathrm{a}_{5}$ & Non-compliant & $\mathrm{X}_{5}$ & Yes \\
\hline 36 & $\mathrm{a}_{6} \rightarrow \mathrm{e}_{61}$ & Non-compliant & $\mathrm{x}_{61}$ & No \\
\hline 37 & $\mathrm{a}_{6} \rightarrow \mathrm{e}_{62}$ & Non-compliant & $\mathrm{x}_{62}$ & No \\
\hline 38 & $a_{7}$ & Non-compliant & $\mathrm{x}_{7}$ & Yes* \\
\hline 39 & $\mathrm{a}_{8}$ & Exit & $\mathrm{X}_{8}$ & Yes \\
\hline
\end{tabular}

* Partially observed 
Table 2: Descriptive statistics of the sample data (1997-2001)

\begin{tabular}{|c|c|c|c|c|c|c|c|}
\hline \multirow{2}{*}{\multicolumn{2}{|c|}{\begin{tabular}{|l|l|} 
Variable & Symbol \\
\multicolumn{2}{|c|}{ Vehicular tailpipe emissio } \\
\end{tabular}}} & \multirow{2}{*}{$\begin{array}{ll} & N \\
n s\end{array}$} & \multirow{2}{*}{\multicolumn{2}{|c|}{ Minimum Maximum }} & \multirow[t]{2}{*}{ Mean } & \multicolumn{2}{|c|}{$\begin{array}{l}\text { Standard Skewness } \\
\text { Deviation }\end{array}$} \\
\hline & & & & & & & \\
\hline $\mathrm{CO}(\%)$ & $\mathrm{CR}_{\mathrm{CO}}$ & 775606 & \begin{tabular}{ll|}
-1.52 \\
\end{tabular} & 14.75 & .47 & 1.07 & 4.46 \\
\hline HC (PPM) & $\mathrm{CR}_{\mathrm{HC}}$ & 741869 & -5000.00 & 55900.00 & 180.04 & 1062.96 & 13.08 \\
\hline NO (PPM) & $\mathrm{CR}_{\mathrm{NO}}$ & 136486 & -249.00 & 6961.00 & 522.00 & 761.36 & 2.42 \\
\hline CO (gm/gal) & $\mathrm{Y}_{\mathrm{CO}}$ & 466640 & 2.88 & 4013.13 & 213.00 & 396.03 & 3.57 \\
\hline $\mathrm{HC}$ (gm/gal) & $\mathrm{Y}_{\mathrm{HC}}$ & 466640 & .05 & 1524.35 & 18.65 & 52.19 & 9.45 \\
\hline NO (gm/gal) & $\mathrm{Y}_{\mathrm{NO}}$ & 89408 & .04 & 269.19 & 24.73 & 31.14 & 2.22 \\
\hline \multicolumn{8}{|c|}{ Quasi-experimental fleet types representing vehicle owners' decision paths } \\
\hline Control fleet & $\mathrm{Q}_{1}$ & 777408 & .00 & 1.00 & .27 & .44 & 1.03 \\
\hline Ineligible fleet & $\mathrm{Q}_{2}$ & 777408 & .00 & 1.00 & .52 & .49 & -.08 \\
\hline Waived fleet & $\mathrm{Q}_{3}$ & 777408 & .00 & 1.00 & .002 & .04 & 20.91 \\
\hline Rest-of-Georgia & $\mathrm{Q}_{4}$ & 777408 & .00 & 1.00 & .10 & .30 & 2.63 \\
\hline Missing fleet & $\mathrm{Q}_{5}$ & 777408 & .00 & 1.00 & .03 & .19 & 4.84 \\
\hline Retest pass & $\mathrm{Q}_{6}$ & 777408 & .00 & 1.00 & .01 & .13 & 7.06 \\
\hline Migrated pass & $\mathrm{Q}_{7}$ & 777408 & .00 & 1.00 & .008 & .09 & 10.62 \\
\hline Retest fail & $\mathrm{Q}_{8}$ & 777408 & .00 & 1.00 & .003 & .06 & 16.25 \\
\hline Migrated fail & $\mathrm{Q}_{9}$ & 777408 & .00 & 1.00 & .001 & .03 & 29.80 \\
\hline Missing fail & $\mathrm{Q}_{10}$ & 777408 & .00 & 1.00 & .003 & .05 & 17.19 \\
\hline Missing pass & $\mathrm{Q}_{11}$ & 777408 & .00 & 1.00 & .03 & .17 & 5.37 \\
\hline \multicolumn{8}{|c|}{ Vehicular characteristics } \\
\hline $\begin{array}{l}\text { Vehicle age } \\
\text { (years) }\end{array}$ & $\mathrm{R}_{1}$ & 777408 & -2 & 40 & 5.40 & 4.62 & 1.35 \\
\hline Vehicle type & $\mathrm{R}_{2}$ & 733080 & 0 & 1 & .38 & .48 & .50 \\
\hline FORD & $\mathrm{R}_{3}$ & 777408 & .00 & 1.00 & .16 & .37 & 1.76 \\
\hline GM & $\mathrm{R}_{4}$ & 777408 & .00 & 1.00 & .19 & .39 & 1.52 \\
\hline CHRYSLER & $\mathrm{R}_{5}$ & 777408 & .00 & 1.00 & .08 & .28 & 2.91 \\
\hline HONDA & $\mathrm{R}_{6}$ & 777408 & .00 & 1.00 & .07 & .26 & 3.13 \\
\hline TOYOTA & $\mathrm{R}_{7}$ & 777408 & .00 & 1.00 & .07 & .25 & 3.29 \\
\hline NISSAN & $\mathrm{R}_{8}$ & 777408 & .00 & 1.00 & .05 & .22 & 3.88 \\
\hline MAZDA & $\mathrm{R}_{9}$ & 777408 & .00 & 1.00 & .02 & .15 & 5.99 \\
\hline MITSUBISHI & $\mathrm{R}_{10}$ & 777408 & .00 & 1.00 & .01 & .11 & 8.81 \\
\hline MERCEDES & $\mathrm{R}_{11}$ & 777408 & .00 & 1.00 & .01 & .10 & 9.38 \\
\hline VOLVO & $\mathrm{R}_{12}$ & 777408 & .00 & 1.00 & .01 & .09 & 9.85 \\
\hline VW & $\mathrm{R}_{13}$ & 777408 & .00 & 1.00 & .007 & .08 & 11.36 \\
\hline ISUZU & $\mathrm{R}_{14}$ & 777408 & .00 & 1.00 & .008 & .09 & 10.91 \\
\hline $\begin{array}{l}\text { Other } \\
\text { Manufacturers }\end{array}$ & $\mathrm{R}_{15}$ & 777408 & .00 & 1.00 & .26 & .44 & 1.07 \\
\hline USA & $\mathrm{R}_{16}$ & 777408 & .00 & 1.00 & .60 & .48 & -.43 \\
\hline JAPAN & $\mathrm{R}_{17}$ & 777408 & .00 & 1.00 & .15 & .36 & 1.86 \\
\hline CANADA & $\mathrm{R}_{18}$ & 777408 & .00 & 1.00 & .09 & .29 & 2.75 \\
\hline GERMANY & $\mathrm{R}_{19}$ & 777408 & .00 & 1.00 & .02 & .170 & 5.52 \\
\hline MEXICO & $\mathrm{R}_{20}$ & 777408 & .00 & 1.00 & .02 & .15 & 6.30 \\
\hline SWEDEN & $\mathrm{R}_{21}$ & 777408 & .00 & 1.00 & .01 & .121 & 7.98 \\
\hline KOREA & $\mathrm{R}_{22}$ & 777408 & .00 & 1.00 & .008 & .09 & 10.45 \\
\hline UK & $\mathrm{R}_{23}$ & 777408 & .00 & 1.00 & .003 & .05 & 17.00 \\
\hline Other countries & $\mathrm{R}_{24}$ & 777408 & .00 & 1.00 & .05 & .23 & 3.78 \\
\hline AIR & $\mathrm{R}_{25}$ & 716710 & 0 & 1 & .25 & .43 & 1.16 \\
\hline TWC & $\mathrm{R}_{26}$ & 716715 & 0 & 1 & .96 & .18 & -5.01 \\
\hline EGR & $\mathrm{R}_{27}$ & 714765 & 0 & 1 & .82 & .38 & -1.65 \\
\hline CLL & $\mathrm{R}_{28}$ & 716714 & 0 & 1 & .97 & .17 & -5.26 \\
\hline TAC & $\mathrm{R}_{29}$ & 716714 & 0 & 1 & .14 & .34 & 2.10 \\
\hline
\end{tabular}




\begin{tabular}{|c|c|c|c|c|c|c|c|}
\hline OXY & $\mathrm{R}_{30}$ & 716711 & 0 & 1 & .03 & .16 & 5.84 \\
\hline PCV & $\mathrm{R}_{31}$ & 716715 & 0 & 1 & 1.00 & .05 & -19.02 \\
\hline \multicolumn{8}{|c|}{ Atmospheric and physical conditions at the time of remote sensing measurement } \\
\hline \begin{tabular}{|l} 
Ambient \\
temperature $(\mathrm{F})$
\end{tabular} & $\mathrm{S}_{1}$ & \begin{tabular}{|c|}
777408 \\
\end{tabular} & 17.00 & 97.00 & 67.91 & 13.83 & -.53 \\
\hline \begin{tabular}{|l} 
Relative \\
humidity (\%)
\end{tabular} & $\mathrm{S}_{2}$ & 777408 & 14.00 & 100.00 & 59.31 & 17.94 & .26 \\
\hline $\begin{array}{l}\text { Atmospheric } \\
\text { pressure } \\
\text { (inches, } \mathrm{Hg} \text { ) }\end{array}$ & $\mathrm{S}_{3}$ & 777408 & 28.49 & 30.22 & 29.01 & .16 & 1.32 \\
\hline Speed (MPH) & $\mathrm{S}_{4}$ & 777408 & .30 & 74.60 & 37.71 & 8.69 & 15 \\
\hline $\begin{array}{l}\text { Acceleration } \\
\text { (MPH/sec) }\end{array}$ & $\mathrm{S}_{5}$ & 777408 & -13.30 & 13.30 & .70 & .57 & .19 \\
\hline $\begin{array}{l}\text { Road gradient } \\
\text { (degrees) }\end{array}$ & $\mathrm{S}_{6}$ & 775273 & -6.00 & 7.50 & .77 & 3.17 & -.12 \\
\hline $\begin{array}{l}\text { Sine (road } \\
\text { gradient) }\end{array}$ & $\mathrm{S}_{6}$ & 775273 & -.997495 & .997495 & .22 & .66 & -.49 \\
\hline $\begin{array}{l}\text { Generation of } \\
\text { remote sensing } \\
\text { instrument }\end{array}$ & $\mathrm{S}_{7}$ & 777408 & 0 & 1 & .22 & .41 & 1.35 \\
\hline \multicolumn{8}{|c|}{ Temporal parameters } \\
\hline 1997 & $\mathrm{~T}_{1}$ & 777408 & .00 & 1.00 & .25 & .43 & 1.15 \\
\hline 1998 & $T_{2}$ & \begin{tabular}{|l|}
777408 \\
\end{tabular} & .00 & 1.00 & .18 & .38 & 1.63 \\
\hline 1999 & $T_{3}$ & 777408 & .00 & 1.00 & .19 & .39 & 1.51 \\
\hline 2000 & $\mathrm{~T}_{4}$ & \begin{tabular}{|l|}
777408 \\
\end{tabular} & .00 & 1.00 & .20 & .40 & 1.46 \\
\hline 2001 & $\mathrm{~T}_{5}$ & \begin{tabular}{|l|l|}
777408 \\
\end{tabular} & .00 & 1.00 & .16 & .36 & 1.82 \\
\hline
\end{tabular}

Table 3: Probability of Compliance

\begin{tabular}{|c|r|r|r|r|r|r|}
\hline $\begin{array}{c}\text { Probability } \\
\text { (Compliance) }\end{array}$ & $\mathbf{1 9 9 7}$ & $\mathbf{1 9 9 8}$ & $\mathbf{1 9 9 9}$ & $\mathbf{2 0 0 0}$ & $\mathbf{2 0 0 1}$ & Average \\
\hline $\begin{array}{c}\text { High emitter } \\
(N=777,408)\end{array}$ & $83.75 \%$ & $37.86 \%$ & $39.28 \%$ & $41.00 \%$ & $36.64 \%$ & $41.22 \%$ \\
\hline $\begin{array}{c}\text { Overall } \\
(N=777,408)\end{array}$ & $98.87 \%$ & $87.17 \%$ & $84.92 \%$ & $85.85 \%$ & $87.13 \%$ & $88.79 \%$ \\
\hline
\end{tabular}

Probability of non-compliance $=[1-$ probability of compliance $]$

* See footnote x for details about 1997 as an outlier 
Table 4: The WLS regression model predicting the effect of compliance behavior of vehicle owners on natural log of vehicular tailpipe CO, HC and NO emissions (dependent variable)

\begin{tabular}{|c|c|c|c|}
\hline Predictors & $\begin{array}{c}\text { CO } \\
(N= \\
430,114)\end{array}$ & $\begin{array}{c}\mathbf{H C} \\
(\mathrm{N}= \\
430,114)\end{array}$ & $\begin{array}{c}\text { NO } \\
(\mathrm{N}=86,588)\end{array}$ \\
\hline & Coefficient & Coefficient & Coefficient \\
\hline Constant & $2.68^{\star \star \star}$ & $3.91^{\star \star \star}$ & 1.35 \\
\hline 1998 & $-0.18^{\star \star \star}$ & $-0.16^{\star \star \star}$ & - \\
\hline 1999 & $-0.42^{\star \star \star}$ & $-0.40^{\star \star \star}$ & - \\
\hline 2000 & $-0.48^{\star \star \star}$ & $-0.57^{\star \star \star}$ & -0.02 \\
\hline 2001 & $-0.66^{\star \star \star}$ & $-1.02^{\star * \star}$ & $-0.29 * * \star$ \\
\hline Ineligible fleet & $0.05^{\star \star \star}$ & $0.04^{\star \star \star}$ & 0.04 \\
\hline 1998 Ineligible fleet & 0.01 & 0.005 & - \\
\hline 1999 Ineligible fleet & $-0.08^{\star \star \star}$ & $-0.06^{\star \star \star}$ & - \\
\hline 2000 Ineligible fleet & -0.004 & $-0.03^{\star \star \star}$ & $0.09^{\star \star}$ \\
\hline 2001 Ineligible fleet & $-0.11^{\star \star \star}$ & $-0.23^{\star \star \star}$ & $0.07^{*}$ \\
\hline Waived fleet & 0.16 & 0.14 & 0.50 \\
\hline 1998 Waived fleet & 0.20 & -0.19 & - \\
\hline 1999 Waived fleet & 0.14 & 0.07 & - \\
\hline 2000 Waived fleet & $-0.29 \star \star$ & -0.11 & -0.06 \\
\hline 2001 Waived fleet & -0.20 & 0.11 & -0.21 \\
\hline Rest-of-Georgia & $0.13^{\star \star \star}$ & $0.09^{\star \star \star}$ & $0.11^{*}$ \\
\hline 1998 Rest-of-Georgia & -0.01 & -0.01 & - \\
\hline 1999 Rest-of-Georgia & $-0.06^{\star \star \star}$ & $-0.08^{\star \star \star}$ & - \\
\hline 2000 Rest-of-Georgia & -0.007 & $-0.03^{\star \star}$ & 0.006 \\
\hline 2001 Rest-of-Georgia & $-0.05^{\star \star \star}$ & $-0.06^{\star \star \star}$ & 0.01 \\
\hline Missing fleet & 0.002 & 0.001 & $0.22^{\star}$ \\
\hline 1998 Missing fleet & $0.09^{\star \star \star}$ & $0.06^{\star \star \star}$ & - \\
\hline 1999 Missing fleet & 0.05 & 0.03 & - \\
\hline 2000 Missing fleet & $0.06^{*}$ & 0.02 & -0.07 \\
\hline 2001 Missing fleet & -0.04 & $0.08^{\star \star}$ & $-0.28^{\star \star}$ \\
\hline Retest pass & $0.34^{\star \star \star}$ & $0.12^{\star \star \star}$ & $0.36^{\star \star}$ \\
\hline 1998 Retest pass & -0.03 & -0.06 & - \\
\hline 1999 Retest pass & 0.03 & 0.01 & - \\
\hline 2000 Retest pass & $-0.11^{* \star}$ & 0.05 & 0.05 \\
\hline 2001 Retest pass & -0.02 & $0.38^{\star \star \star}$ & 0.19 \\
\hline Migrated pass & $0.10^{*}$ & $0.10^{\star \star \star}$ & 0.32 \\
\hline 1998 Migrated pass & - & - & - \\
\hline 1999 Migrated pass & 0.03 & $-0.10^{\star \star}$ & - \\
\hline 2000 Migrated pass & 0.004 & -0.05 & -0.12 \\
\hline 2001 Migrated pass & -0.06 & -0.04 & -0.28 \\
\hline Retest fail & $0.38^{\star \star \star}$ & $0.12^{*}$ & 0.57 \\
\hline 1998 Retest fail & $0.23^{\star \star}$ & 0.13 & - \\
\hline 1999 Retest fail & $0.34^{\star \star \star}$ & $0.17 * \star$ & - \\
\hline 2000 Retest fail & 0.12 & $0.21 * \star$ & 0.08 \\
\hline 2001 Retest fail & -0.04 & $0.40^{\star \star \star}$ & -0.03 \\
\hline Migrated fail & $0.55^{\star \star \star}$ & $0.60^{\star \star \star}$ & 0.18 \\
\hline 1998 Migrated fail & - & $-0.60^{\star \star \star}$ & - \\
\hline 1999 Migrated fail & 0.005 & $-0.51^{\star \star \star}$ & - \\
\hline 2000 Migrated fail & -0.02 & $-0.27^{\star \star \star}$ & 0.02 \\
\hline 2001 Migrated fail & -0.11 & - & 0.18 \\
\hline Missing fail & $0.27^{\star \star}$ & 0.07 & 0.12 \\
\hline 1998 Missing fail & - & - & - \\
\hline 1999 Missing fail & $0.26^{*}$ & 0.08 & - \\
\hline
\end{tabular}




\begin{tabular}{|c|c|c|c|}
\hline 2000 Missing fail & 0.05 & 0.10 & 0.20 \\
\hline 2001 Missing fail & -0.11 & $0.38^{\star \star \star}$ & 0.04 \\
\hline Missing pass & 0.02 & $0.04^{\star \star}$ & $0.17^{\star \star}$ \\
\hline 1998 Missing pass & - & - & - \\
\hline 1999 Missing pass & $0.07^{\star}$ & -0.02 & - \\
\hline 2000 Missing pass & -0.002 & -0.00002 & -0.13 \\
\hline 2001 Missing pass & $-0.10^{\star \star \star \star}$ & $-0.05^{\star \star}$ & $-0.31^{\star \star \star}$ \\
\hline Vehicle age (years) & $0.13^{\star \star \star}$ & $0.01^{\star \star \star}$ & $0.33^{\star \star \star}$ \\
\hline Vehicle age squared & $-0.002^{\star \star \star}$ & $0.004^{\star \star \star}$ & $-0.01^{\star \star \star}$ \\
\hline Vehicle age cubed & $.00001^{\star \star}$ & $-0.0001^{\star \star \star}$ & $0.0002^{\star \star \star}$ \\
\hline Vehicle type & $-0.04^{\star \star \star}$ & $-0.03^{\star \star \star}$ & $0.12^{\star \star \star}$ \\
\hline GM & 0.0003 & $0.02^{\star \star \star}$ & $-0.07^{\star \star \star}$ \\
\hline CHRYSLER & 0.004 & -0.008 & -0.01 \\
\hline HONDA & $0.21^{\star \star \star}$ & $-0.06^{\star \star \star}$ & $-0.20^{\star \star \star}$ \\
\hline TOYOTA & $0.04^{\star \star \star}$ & $-0.01^{*}$ & $-0.08^{\star \star \star}$ \\
\hline NISSAN & $0.07^{\star \star \star}$ & $0.01^{\star \star \star}$ & $-0.03^{*}$ \\
\hline MAZDA & $0.19^{\star \star \star}$ & $0.07^{\star \star \star}$ & 0.001 \\
\hline MITSUBISHI & $0.12^{\star \star \star}$ & $0.12^{\star \star \star}$ & $0.24^{\star \star \star}$ \\
\hline MERCEDES & $-0.24^{\star \star \star}$ & -0.02 & $-0.43^{\star \star \star}$ \\
\hline VOLVO & $0.08^{\star \star \star}$ & 0.004 & $-0.20^{*}$ \\
\hline VW & -0.005 & $0.03^{\star \star}$ & $-0.17^{\star \star \star}$ \\
\hline ISUZU & $0.11^{\star \star \star}$ & -0.01 & -0.02 \\
\hline Other Manufacturers & $0.06^{\star \star \star}$ & -0.002 & $-0.28^{\star \star \star}$ \\
\hline JAPAN & $-0.10^{\star \star \star}$ & $-0.04^{\star \star \star}$ & $-0.11^{\star \star \star}$ \\
\hline CANADA & $0.02^{\star \star \star}$ & $0.01^{\star \star \star}$ & $0.06^{\star \star \star}$ \\
\hline GERMANY & $-0.28^{\star \star \star}$ & $-0.11^{\star \star *}$ & $-0.19 \star \star \star$ \\
\hline MEXICO & $0.04^{\star \star \star}$ & -0.008 & $0.11^{\star \star \star}$ \\
\hline SWEDEN & $-0.44^{\star \star \star}$ & 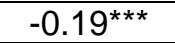 & -0.15 \\
\hline KOREA & 0.03 & $0.11^{\star \star \star}$ & $0.21^{\star \star}$ \\
\hline UK & $-0.32^{\star \star \star}$ & $-0.13^{\star \star \star}$ & $-0.19^{* \star}$ \\
\hline Other countries & $-0.10^{\star}$ & $0.13^{\star \star \star}$ & -0.18 \\
\hline AIR & $0.05^{\star \star \star}$ & $0.05^{\star \star \star}$ & $-0.02^{\star \star}$ \\
\hline TWC & $0.17^{\star \star \star}$ & $-0.06^{\star \star}$ & 0.02 \\
\hline EGR & $-0.11^{\star \star \star}$ & $-0.04^{\star \star \star}$ & $-0.12^{\star \star \star}$ \\
\hline CLL & $0.05^{\star}$ & 0.03 & $-0.45^{\star \star \star}$ \\
\hline TAC & $0.28^{\star \star \star}$ & $0.08^{\star \star \star}$ & 0.02 \\
\hline OXY & $0.22^{\star \star \star}$ & -0.02 & 0.09 \\
\hline PCV & $0.48^{\star \star \star}$ & $0.08^{\star \star \star}$ & $0.14^{\star \star}$ \\
\hline Ambient temperature $(\mathrm{F})$ & $0.003^{\star \star \star}$ & $-0.001^{\star \star \star}$ & $-0.005^{\star \star \star}$ \\
\hline Relative humidity (\%) & $-0.004^{\star \star \star}$ & $-0.001^{\star \star \star}$ & $-0.004^{\star \star \star}$ \\
\hline Pressure (inches, $\mathrm{Hg}$ ) & 0.01 & $-0.05^{\star \star \star}$ & 0.009 \\
\hline Speed (MPH) & $0.004^{\star \star \star}$ & $0.008^{\star \star \star}$ & $0.02^{\star \star \star}$ \\
\hline Acceleration (MPH/sec) & -0.004 & $-0.04^{\star \star \star}$ & $0.07^{\star \star \star}$ \\
\hline Sine (road gradient) & $-0.04^{\star \star \star}$ & $0.006^{\star \star \star}$ & $-0.04^{\star \star \star}$ \\
\hline Generation of instrument & $-0.13^{\star \star \star}$ & $-1.22^{\star \star \star}$ & - \\
\hline Adj-R ${ }^{2}$ & $92.73 \%$ & $84.12 \%$ & $80.40 \%$ \\
\hline Root MSE & 2.43 & 1.92 & 2.45 \\
\hline F test statistic & 61671.17 & 24751.48 & 5075.27 \\
\hline
\end{tabular}

(1) Coefficient value with one * shows significance at $90 \%$ confidence level; two ** at 95\% confidence level; and three ${ }^{* * *}$ at $99 \%$ confidence level.

(2) The Log-linear WLS model is run with no constant parameter. Rather, the weight variable is added as an explanatory variable, whose coefficient is reported in place of the constant. 


\section{References}

Brown, R. V., Kahr, A. S. and Peterson E. (1974). Decision Analysis for the Manager. Holt, Rinehart \& Winston, New York.

Cook, T. and Campbell, D. T. (1979). Quasi-Experimentation: Design \& Analysis Issues for Field Settings. Houghton Mifflin, Boston.

Davidson, R. and MacKinnon, J. G. (1993) Estimation and Inference in Econometrics. Oxford University Press, New York.

Environmental Protection Agency (EPA) (2002). Guidance on Use of Remote Sensing for Evaluation of I/M Program Performance. EPA 420-B-02-001. July 2002. Air and Radiation. United States Environmental Protection Agency

Harrington, W., McConnell, V. and Cannon, M. (1998). A Behavioral Analysis of EPA's Mobile Emission Factor Model. Discussion paper 98-47. Resources for the Future, Washington DC.

Harrington, W. and McConnell, V. (1999). Coase and Car Repair: Who Should Be Responsible for Emissions of Vehicles in Use? Resources for the Future, Washington DC.

Harrington, W., McConnell, V. and Ando, A. (2000). Are Vehicle Emission Inspection Programs Living up to Expectations? Transportation Research Part D-Transport and Environment 5, 153-72.

Harsanyi, J. C. (1967). Game with Incomplete Information Played by "'Bayesian"'" Players, Part I-III. Management Science 14, 150-182, 320-334, 486-502.

Holloway, C. A. (1979). Decision Making under Uncertainty: Models and Choices. Prentice-Hall, Englewood Cliffs, NJ. 
Lawson, D. R. (1993). "Passing the Test"-- Human Behavior and California's Smog Check Program. Journal of the Air and Waste Management Association 43, 15671575.

Lawson, D. R. (1995). The Costs of "M" in I/M--Reflections on Inspection/Maintenance Programs. Journal of the Air and Waste Management Association 45, 465-476.

Lawson, D. R., Groblicki, P. J., Stedman, D., Bishop, G. A. and Guenther, P. L. (1990). Emissions from in-Use Motor Vehicles in Los Angeles: A Pilot Study of Remote Sensing and the Inspection and Maintenance Program. Journal of the Air and Waste Management Association 40, 1096-1105.

Meyer, B. D. (1995). Natural and Quasi-Experiments in Economics. Journal of Business and Economic Statistics 13, 151-161.

National Research Council (NRC). (2001). Evaluating Vehicle Inspection and Maintenance Programs: National Research Council. National Academy Press, Washington DC.

Raiffa, H. (1968). Decision Analysis. Addison-Wesley, Reading, MA.

Savage, L. J. (1954). The Foundations of Statistics. Wiley, New York.

Stedman, D., Bishop, G. A., Aldrete, P. and Slott, R. S. (1997). On-Road Evaluation of an Automobile Emission Test Program. Environmental Science \& Technology 31, 927-31.

Stedman, D. H., Bishop, G. A. and Slott, R. S. (1998). Repair Avoidance and Evaluating Inspection and Maintenance Programs. Environmental Science \& Technology 32, 1544-45. 
Von Neumann, J. and Morgenstern, O. (1944). Theory of Games and Economic Behavior. Princeton University Press, Princeton.

Wenzel, T. (1999). Evaluation of Arizona's Enhanced I/M Program. Presentation at the Ninth Road Vehicle Emissions Workshop, San Diego, CA.

Wenzel, T., Gumerman, E., Singer, B. and Sawyer, R. (2000). Evaluation of the Enhanced Smog Check Program: A Report to the California Inspection and Maintenance Review Committee.

White, H. (1980). A Heteroskedasticity-Consistent Covariance Matrix Estimator and a Direct Test for Heteroskedasticity. Econometrica 48, 817-838.

Winterfeldt, D. V. and Edwards, W. (1986). Decision Analysis and Behavioral Research. Cambridge University Press, New York.

Zia, A. (2004) Cooperative and Non-Cooperative Decision Behaviors in Response to the Inspection and Maintenance Program in the Atlanta Airshed, 1997-2001. Ph.D. Dissertation, School of Public Policy, Georgia Institute of Technology, Atlanta. 


\section{The Figure Captions}

Figure 1: A conceptual framework of quasi-experimental research design

Figure 2: A decision tree showing sets of actions, events and outcomes faced by a vehicle owner in the Atlanta airshed due to the IM program regulations

Figure 3: The sampling methodology for characterizing vehicle fleets (shown in bold font) by using the on road emissions data

Figure 4: Observations as a percent of total sample at remote sensing sites in Atlanta $(1997-2001)$

Figure 5: Vehicular tailpipe emissions of CO, HC and NO distributed by vehicle age and observation year

Figure 6: Annual trend of CO, HC and NO emission factors by 11 fleet types 


\section{Figures}

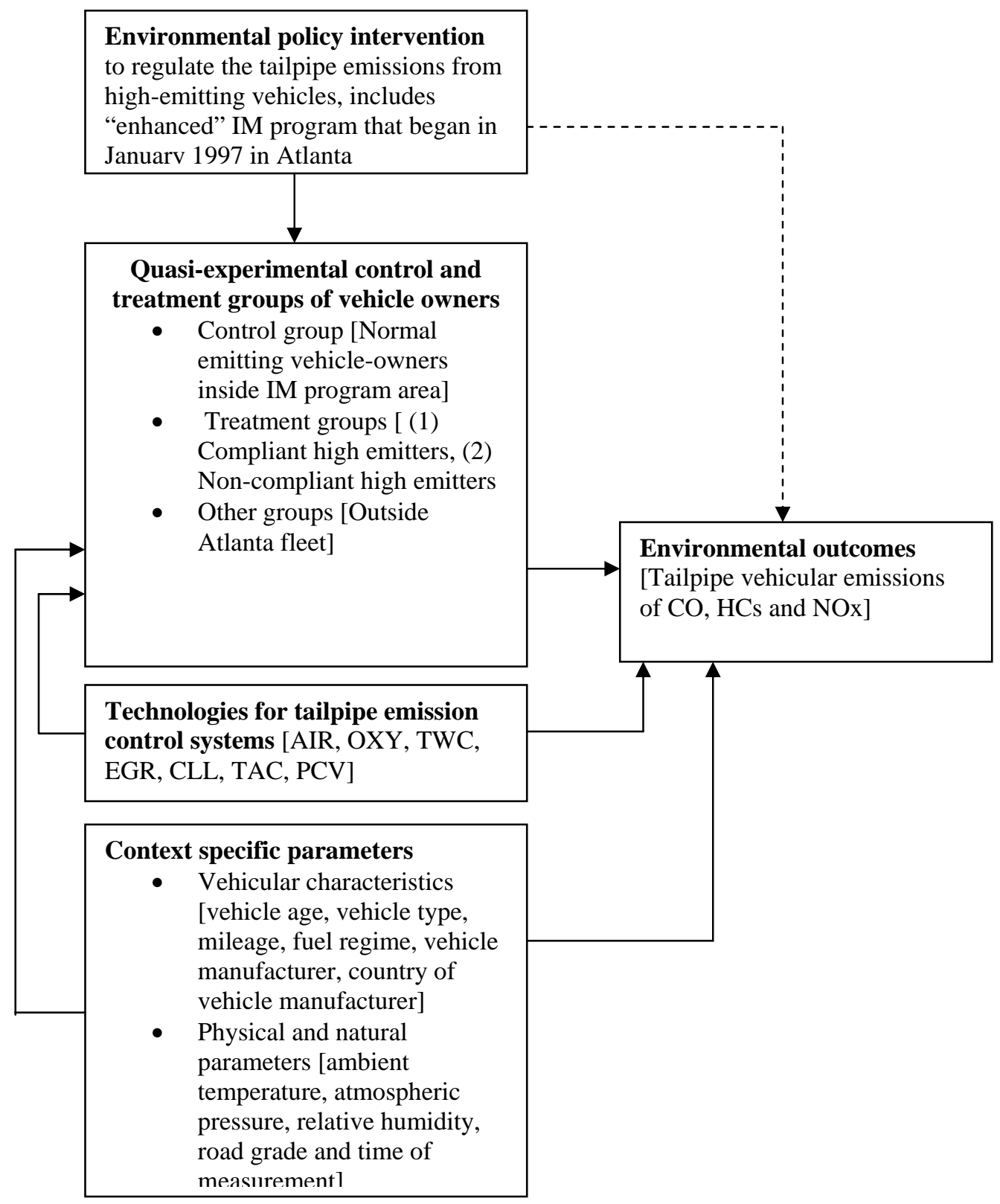

Figure 1: A conceptual framework of quasi-experimental research design 


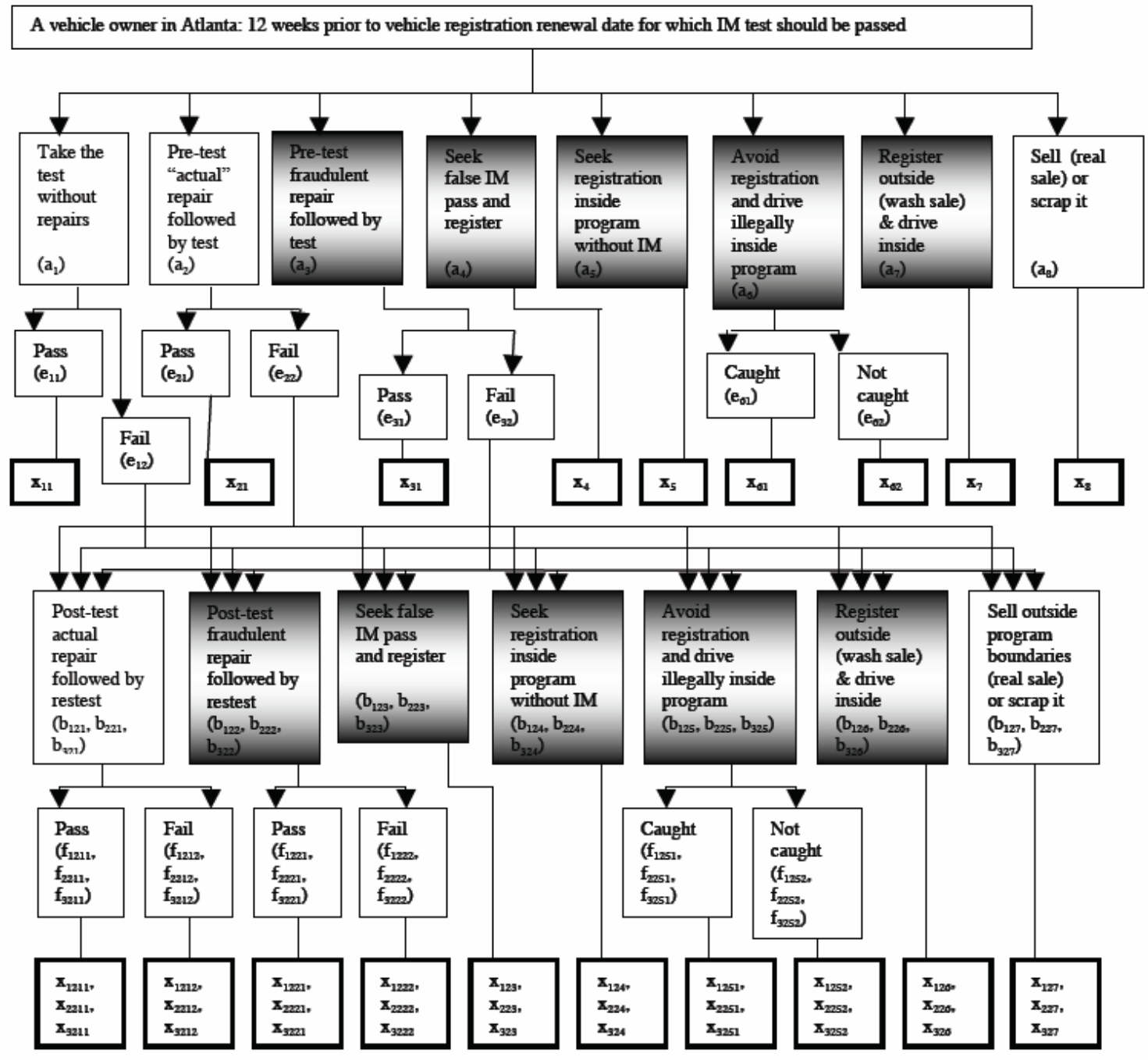

Figure 2: Decision tree showing sets of actions, events and outcomes faced by a vehicle owner in the Atlanta airshed due to the IM program regulations (shaded boxes show non-compliant actions) 


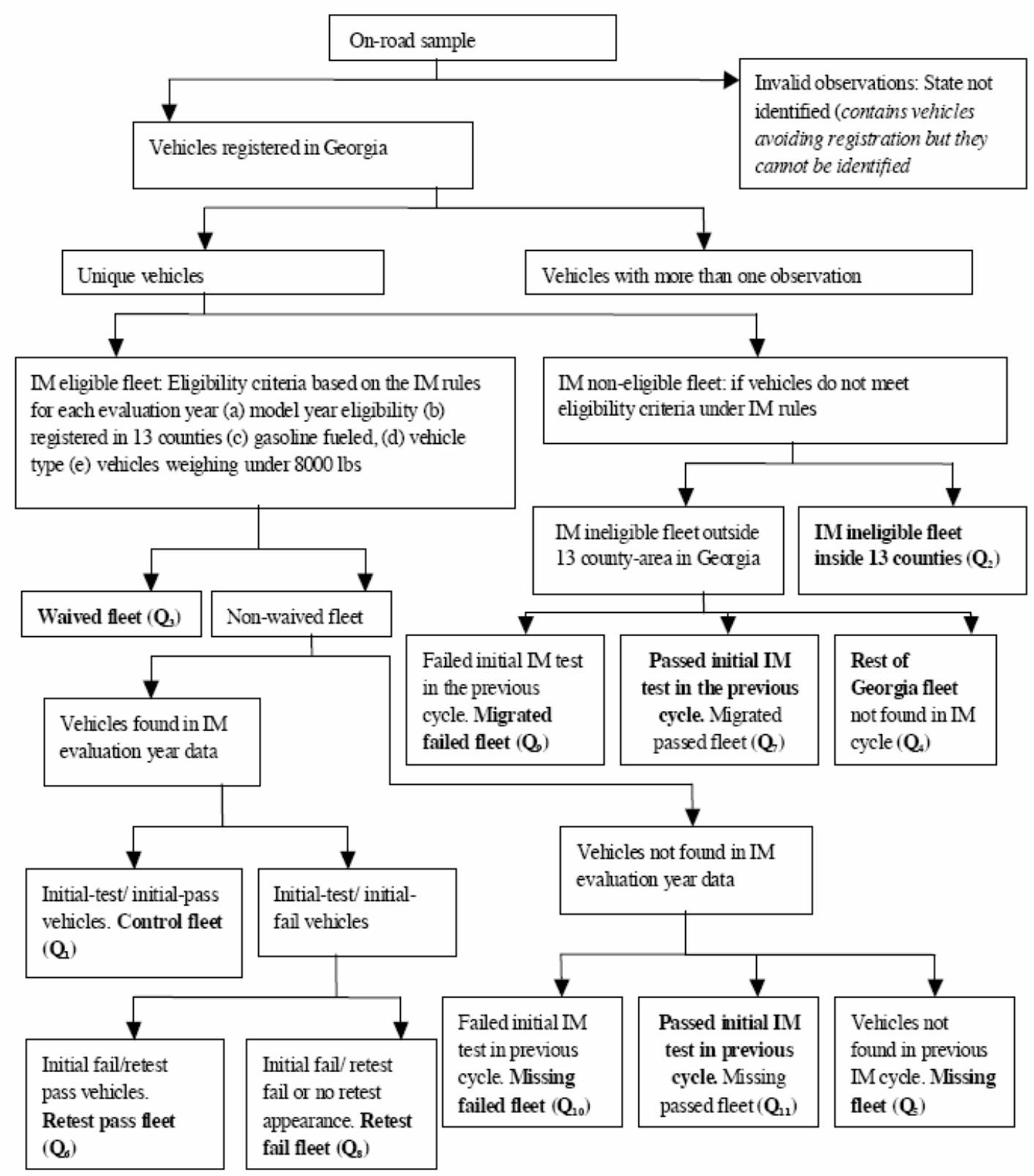

Figure 3: The sampling methodology for characterizing compliant and non-compliant vehicle fleets (shown in bold font) by using on-road emissions data 


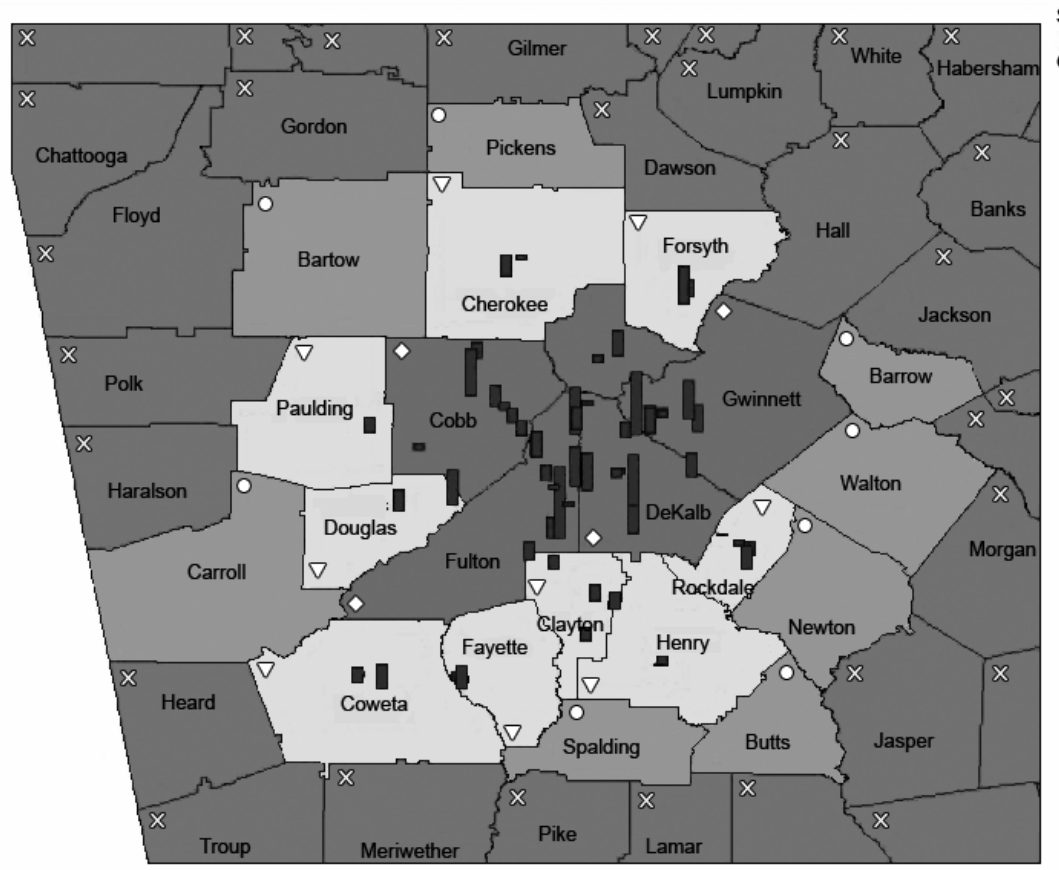

Sites
Georgia Counties

$\checkmark$ Basic and enhanced IM program

$\nabla$ Enhanced IM program

C Counties in the Atlanta MSA without IM

$X$ Counties outside the Atlanta MSA<smiles>Nc1cc(N)cc(F)c1</smiles>

40

0

40

80 Miles

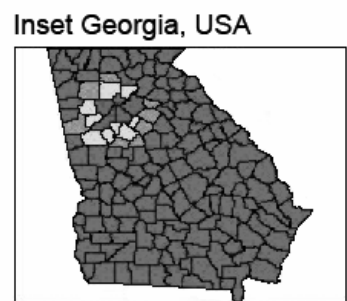

Figure 4: Observations as a percent of total sample at remote sensing sites in Atlanta (1997-2001) 


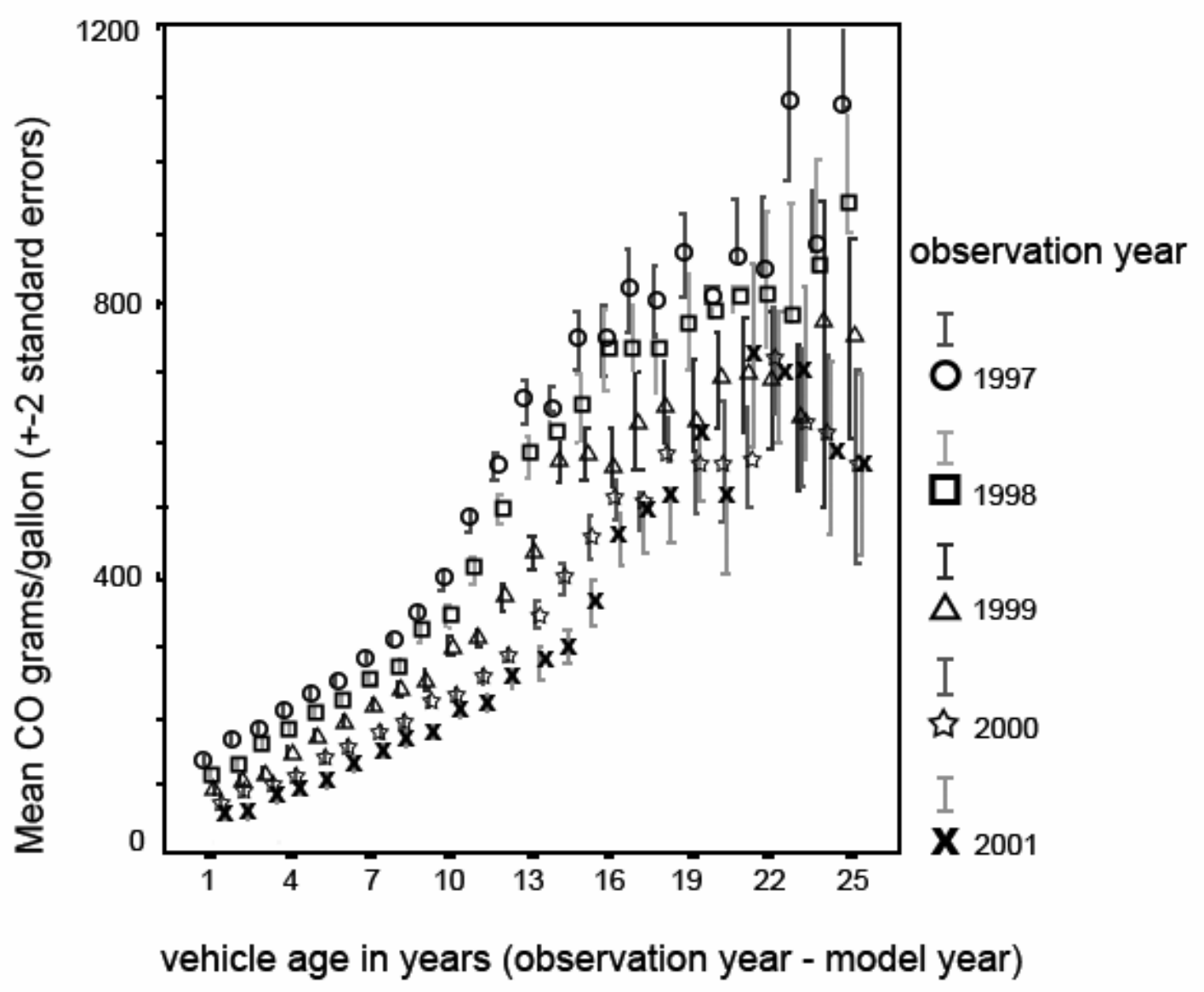




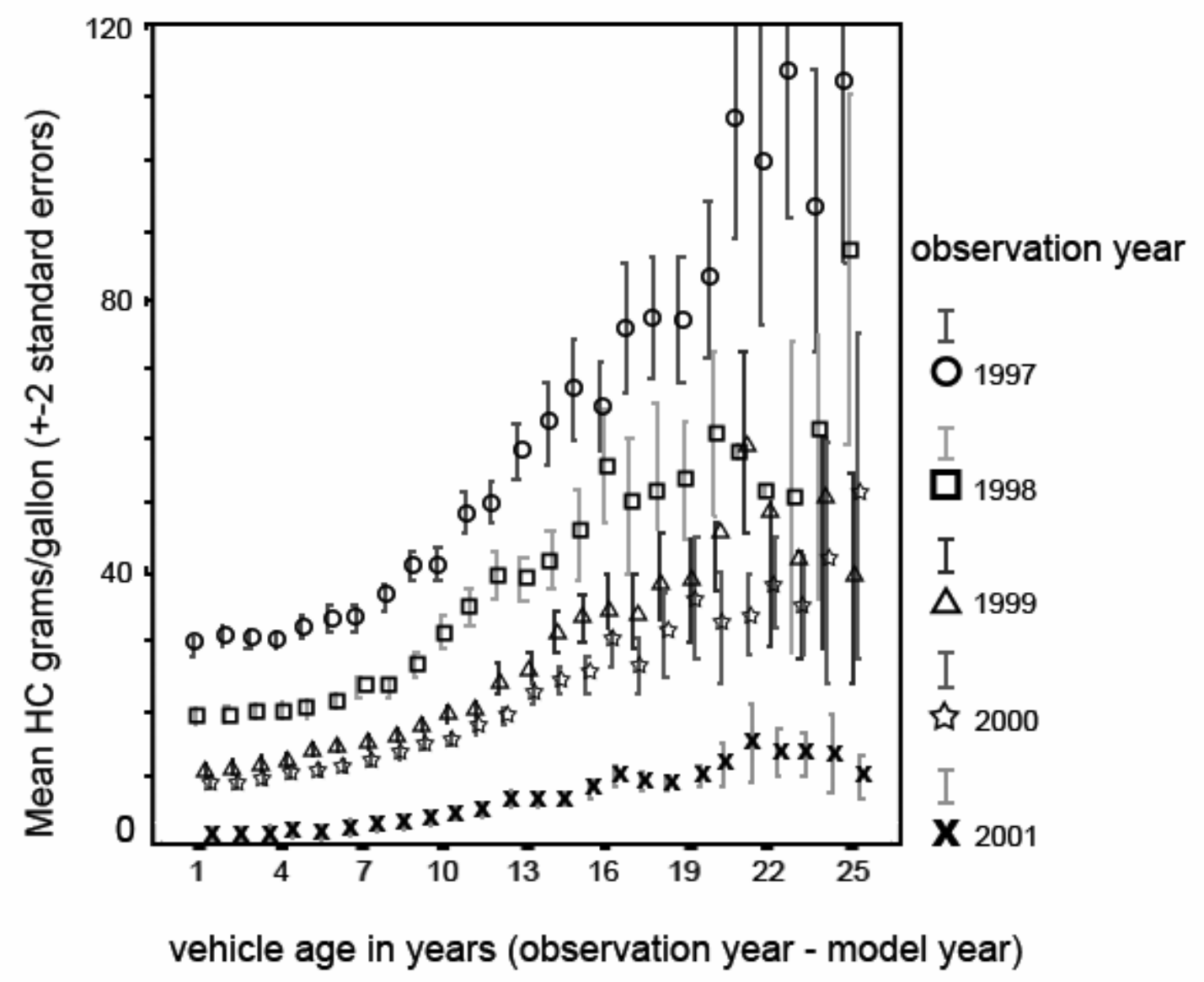




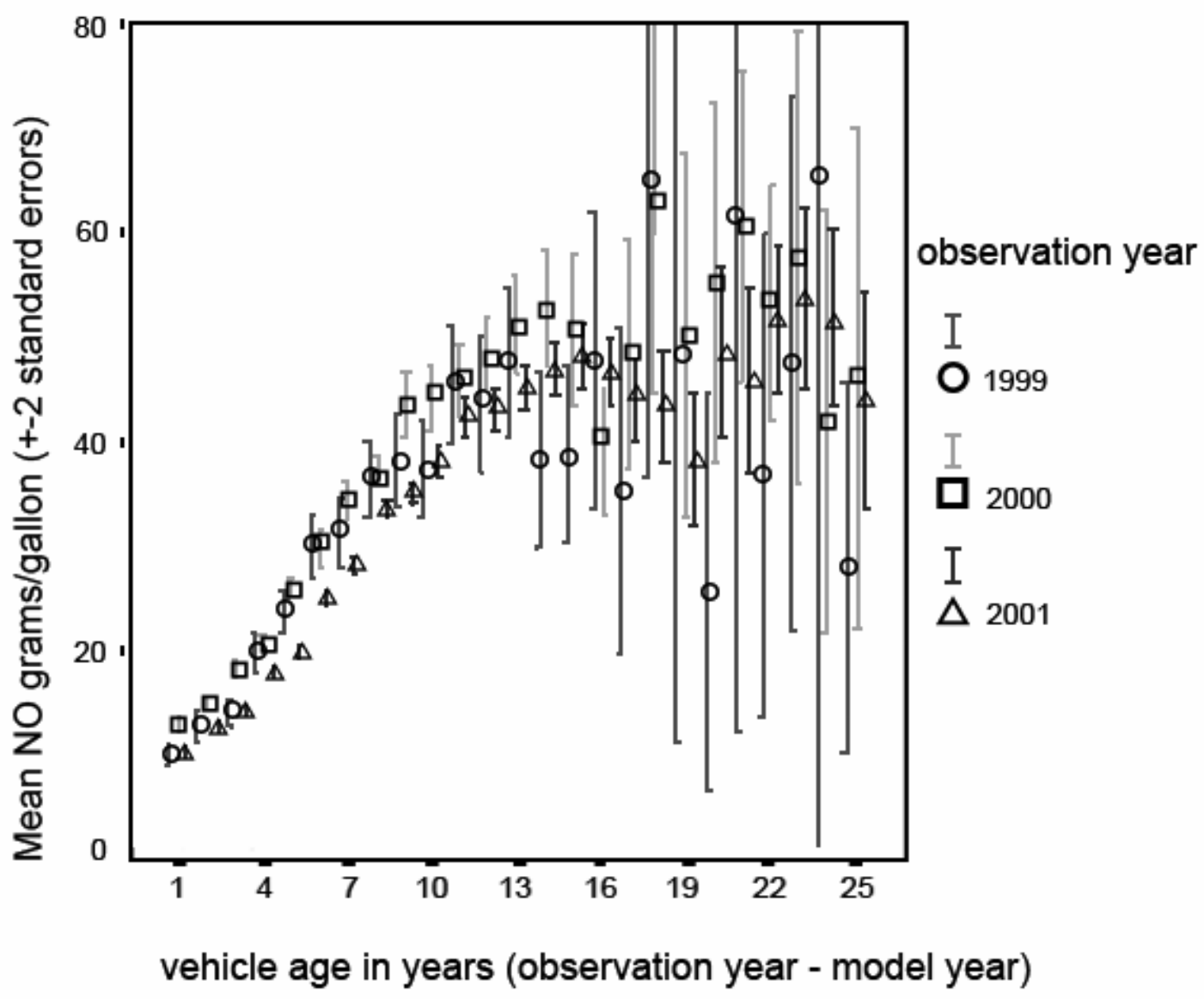

Figure 5: Vehicular tailpipe emissions of $\mathrm{CO}, \mathrm{HC}$ and NO distributed by vehicle age and observation year 


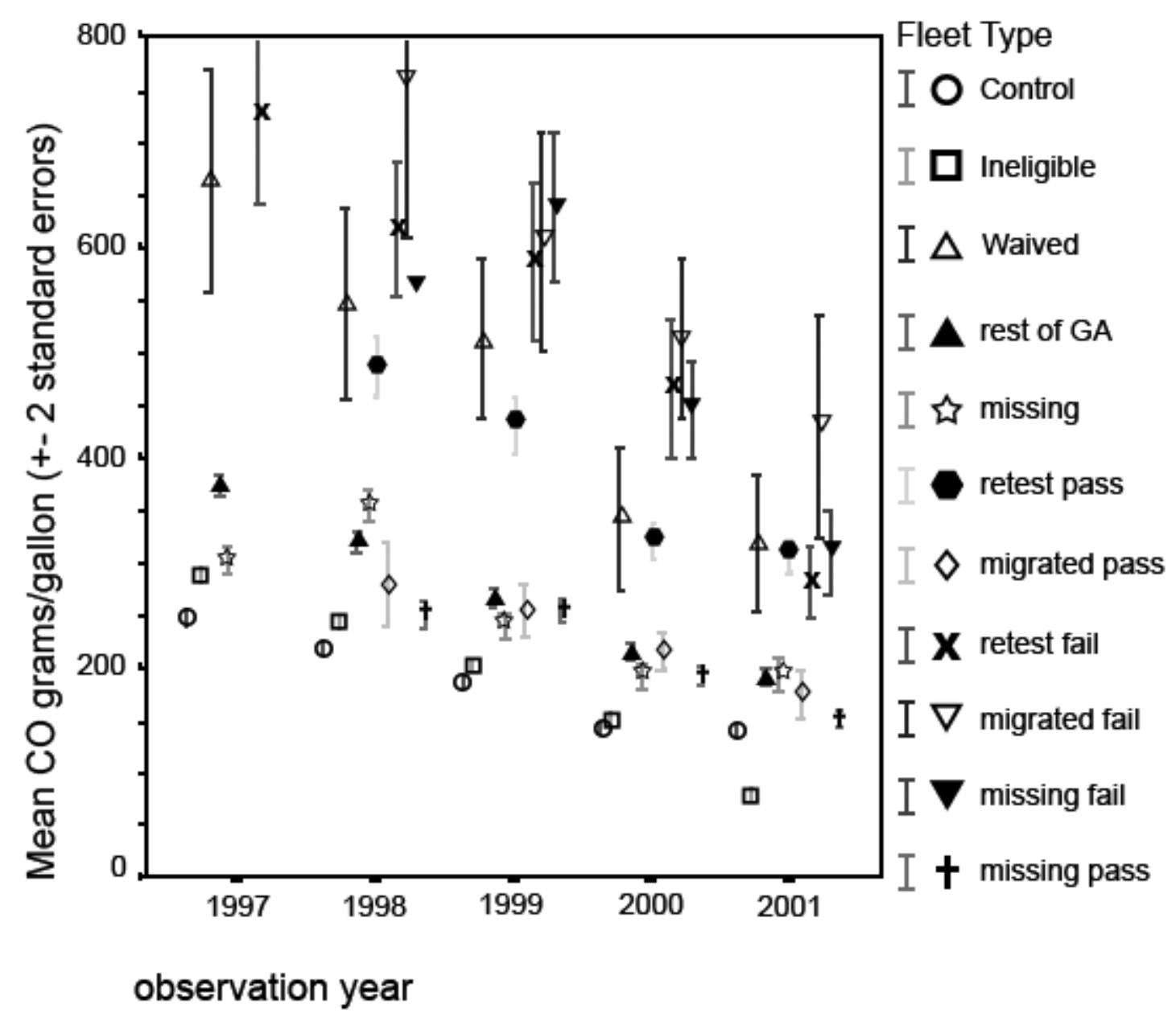




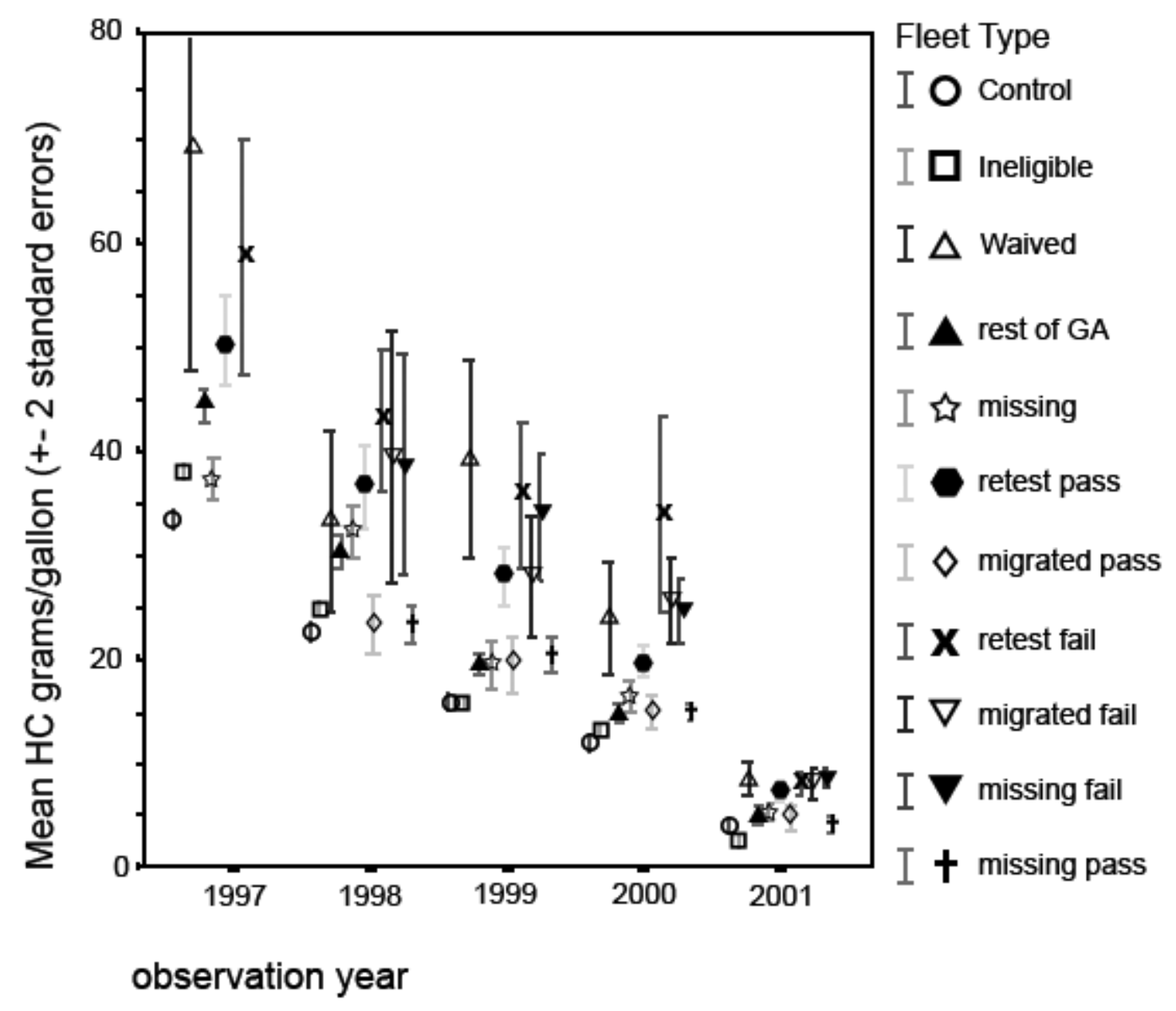




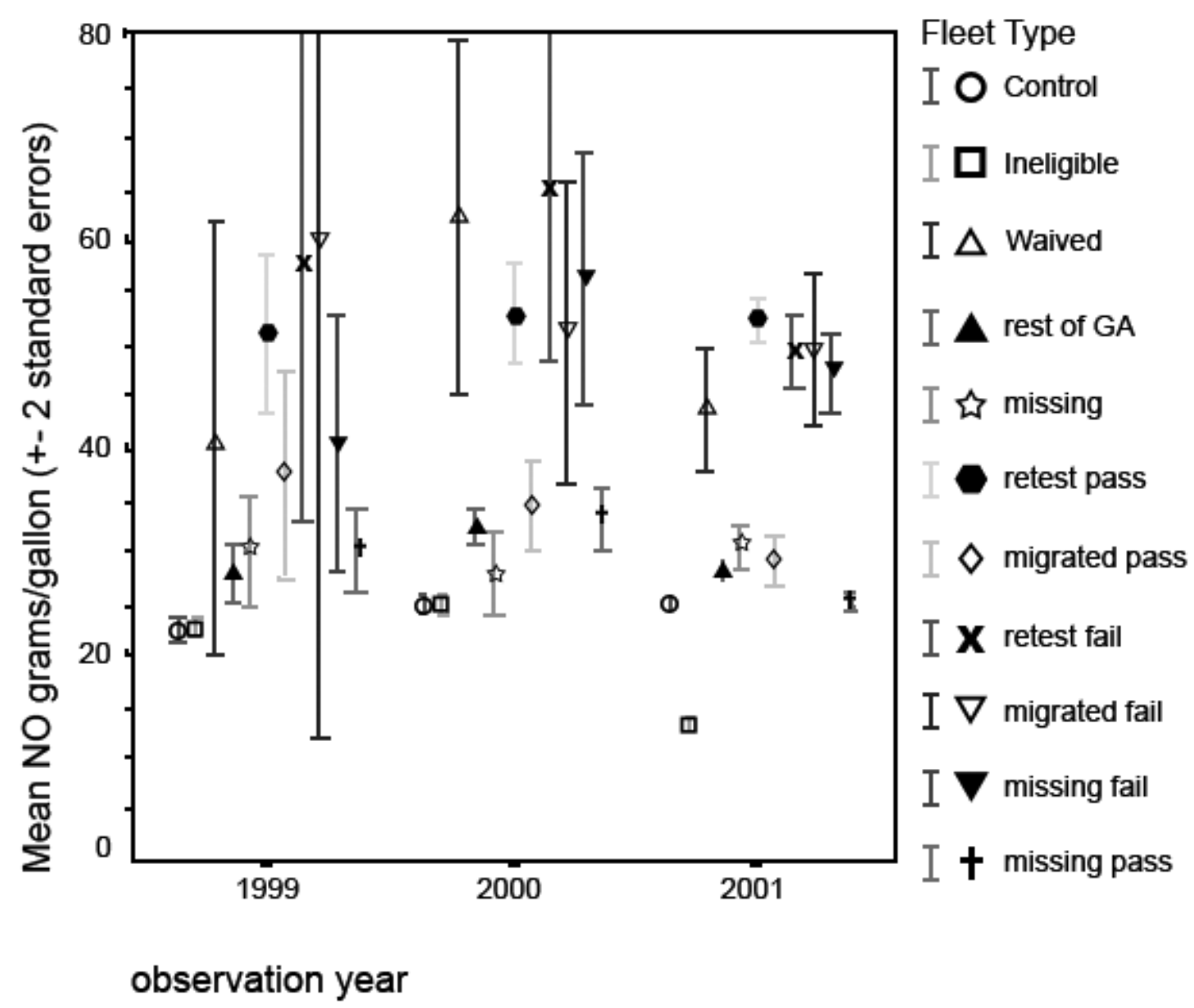

Figure 6: Annual trend of CO, HC and NO emission factors by 11 fleet types 